Article

\title{
Thermal State of the Blake Ridge Gas Hydrate Stability Zone (GHSZ)_-Insights on Gas Hydrate Dynamics from a New Multi-Phase Numerical Model
}

\author{
Ewa Burwicz *(1) and Lars Rüpke \\ GEOMAR Helmholtz Centre for Ocean Research Kiel, Wischhofstrasse 1-3, D-24148 Kiel, Germany \\ * Correspondence: eburwicz@geomar.de
}

Received: 5 June 2019; Accepted: 24 August 2019; Published: 3 September 2019

\begin{abstract}
Marine sediments of the Blake Ridge province exhibit clearly defined geophysical indications for the presence of gas hydrates and a free gas phase. Despite being one of the world's best-studied gas hydrate provinces and having been drilled during Ocean Drilling Program (ODP) Leg 164, discrepancies between previous model predictions and reported chemical profiles as well as hydrate concentrations result in uncertainty regarding methane sources and a possible co-existence between hydrates and free gas near the base of the gas hydrate stability zone (GHSZ). Here, by using a new multi-phase finite element (FE) numerical model, we investigate different scenarios of gas hydrate formation from both single and mixed methane sources (in-situ biogenic formation and a deep methane flux). Moreover, we explore the evolution of the GHSZ base for the past 10 Myr using reconstructed sedimentation rates and non-steady-state P-T solutions. We conclude that (1) the present-day base of the GHSZ predicted by our model is located at the depth of $\sim 450 \mathrm{mbsf}$, thereby resolving a previously reported inconsistency between the location of the BSR at ODP Site 997 and the theoretical base of the GHSZ in the Blake Ridge region, (2) a single in-situ methane source results in a good fit between the simulated and measured geochemical profiles including the anaerobic oxidation of methane (AOM) zone, and (3) previously suggested 4 vol. $\%-7$ vol. $\%$ gas hydrate concentrations would require a deep methane flux of $\sim 170 \mathrm{mM}$ (corresponds to the mass of methane flux of $1.6 \times 10^{-11} \mathrm{~kg} \mathrm{~s}^{-1} \mathrm{~m}^{-2}$ ) in addition to methane generated in-situ by organic carbon (POC) degradation at the cost of deteriorating the fit between observed and modelled geochemical profiles.
\end{abstract}

Keywords: gas hydrate; numerical modeling; methane; Blake Ridge

\section{Introduction}

Gas hydrates (clathrates) are ice-like crystalline cage structures containing various greenhouse gases such as methane or $\mathrm{CO}_{2}$, which are stored within their crystallographic structure. The combination of low-temperature and high-pressure conditions defines the gas hydrate stability zone (GHSZ), which is a proxy to the abundance of gas hydrates in marine sediments. Marine gas hydrate deposits were discovered mainly along continental margins (slope and rise) where water depths exceed $\sim 300 \mathrm{~m}$ and bottom water temperatures are sufficiently low. Their potential impact on climate change [1-4], slope stability [5,6], and global energy reserves [7-9] have drawn considerable public and scientific attention over the last decades. Yet, the amount of gas hydrates present on a global scale is still under debate $[7,10,11]$. Several numerical models of a different complexity have been developed to estimate the potential amounts of clathrates within marine sediments [12-17]. Global estimates range from $500 \mathrm{Gt}$ up to $75,000 \mathrm{Gt}$ of carbon and show a variation of several orders of magnitude. In comparison, the world's conventional gas endowment has been estimated at 2.567 TBOE (trillion barrels of oil equivalent) $=0.436 \times 10^{15} \mathrm{~m}^{3}$ of natural gas [18], which is about $0.5 \%-40 \%$ of the total methane gas 
volume potentially trapped in gas hydrates (from $1.06 \times 10^{15} \mathrm{~m}^{3} \mathrm{CH}_{4}$ up to $120.78 \times 10^{15} \mathrm{~m}^{3} \mathrm{CH}_{4}$ at STP condition).

One of the best-known gas hydrate provinces, the Blake Ridge Site offshore South Carolina, has been widely investigated during the Ocean Drilling Program (ODP) Leg 164. Seismic profiles across two (995 and 997) out of the three $(955,997$, and 994) drill sites show clearly defined BSRs sub-parallel to the seafloor. Their seismic signature is characteristic for the boundary between free gas- and hydrate-bearing sediments in that high-amplitude seismic reflections (corresponding to the presence of a free gas) are overlain by low-amplitude seismic reflections, which is known as the 'blanking effect' [19]. The depth of a seismic BSR typically corresponds to the base of the GHSZ, which defines the sharp phase boundary between the stability fields of gas hydrate and free gas. However, at the Blake Ridge province, BSR depths at the 995 and 997 sites ( 440-450 mbsf) do not correspond with the bottom of the thermodynamic GHSZ ( $520 \mathrm{mbsf})$ [20-22]. It has been suggested that this discrepancy is caused by a co-existence of free gas and hydrate within the GHSZ. The seismic data appears to be consistent with such a co-existence of phases, which allows for the possibility of free methane gas migration within the GHSZ $[20,23,24]$. However, free gas becomes the wetting phase when co-existing with pore fluids, so that it is generally assumed that a relatively high free gas concentration, possibly from a deep thermogenic source, is required to initialize such a process although the source of such flux is still debatable. Several studies have pointed to the possibility that a deeply sourced upward methane flux is involved in the formation of Blake Ridge gas hydrates [25,26]. Following this hypothesis, the potential rate of pore fluid flux into the GHSZ has been calculated from halogen geochemical analysis [27] and was estimated at $0.2 \mathrm{~mm} \cdot$ year $^{-1}$ but such geochemically inferred flux estimates remain debated. Support for a deep fluid/methane flux also comes from previous modeling attempts [25-31], which failed to reproduce sufficiently high hydrate and free gas concentrations when assuming a single biogenic source of methane, constant sedimentation rates over the entire history of the basin, and no additional deep methane flux. Paradoxically, the inferred deep methane flux is inconsistent with the strongly depleted $\delta^{13} \mathrm{C}$ isotopic signature of methane gas at the Blake Ridge Site [32], which points to a purely microbial in-situ gas hydrate origin [22,33].

Here, by applying a new numerical model that overcomes some restrictions of previous modeling attempts such as allowing for variable sedimentation rates and seafloor organic carbon (POC) concentrations through time, we investigate (1) if the Blake Ridge gas hydrates could have formed from a single in-situ microbial source or rather from a mixed source (microbial + deep-sourced methane flux), (2) the discrepancy between the observed BSR depth and theoretical base of the GHSZ, and (3) the impact of variations in sediment deposition and compaction on fluid and gas flow regimes coupled with bio-chemical reactions occurring within the sediment column.

\subsection{The Blake Ridge Site Geological Setting and Characterization}

The Blake Ridge is situated offshore from the southeastern US coast (South Carolina) as a stable Neogene and Quaternary sediment drift deposit (Figure 1). Sediment wave structures along the Blake Ridge southern flanks result from the presence of the Gulf Stream that mixes with the Western boundary undercurrent (WBUC) at moderate bottom water depths [34]. Since this area is strongly influenced by the Gulf Stream, it is particularly vulnerable to changes in ocean circulation that might occur under a warming climate. Large quantities of methane gas hydrates locked within Blake Ridge sediments contribute to the discussion on submarine slope failure scenarios and other natural hazards that might take place if the hydrate reservoir becomes unstable $[3,35,36]$. Sediments at the Blake Ridge are mostly homogenous and contain mostly clays, claystones, and fine-grained mudstones [20] that were deposited at relatively high sedimentation rates [37].

The Blake Ridge Site is characterized by low fluid advection rates and a mostly homogenous sediment composition with clay fractions of $60 \%-70 \%$ and limited changes in a grain size over the entire depth profile [20]. At present, sediments are deposited with an organic carbon content that generally varies between $0.5 \mathrm{wt} . \%-1 \mathrm{wt} . \%$ [22] with maximum values of up to $1.6 \mathrm{wt} . \%$ [20,33], which is typical 
for organically rich oceanic margin sediments. The source of sedimentary organic matter at Sites 994, 996, and 997 has been described as mainly marine [38]. Rapid burial of organic matter has probably resulted in the high preservation of POC with depth in the Blake Ridge region. Isotopically lighter terrestrial POC might be additionally transported into the system from the neighboring continental shelf. The isotopic composition of low molecular-weight hydrocarbons (methane and ethane) suggest a microbial origin $\left(\delta^{13} \mathrm{C}_{\mathrm{CH} 4}\right.$ values more negative than $-61 \%$ o). According to the relationship between $\delta^{13} \mathrm{C}_{\mathrm{CH} 4}$ and $\delta \mathrm{D}_{\mathrm{CH} 4}$ values, the production of methane occurred via $\mathrm{CO}_{2}$ reduction at all Leg 164 Sites [38] and the pools of $\mathrm{CH}_{4}$ and $\mathrm{CO}_{2}$ were decoupled from each other, which implies an open carbon system during diagenetic processes.

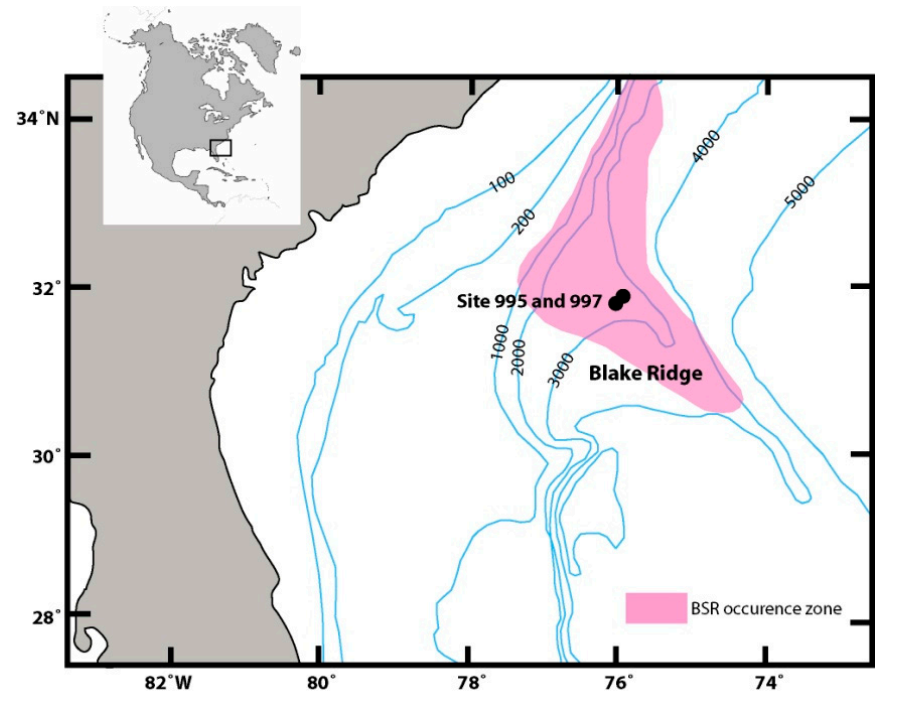

Figure 1. Bathymetric map of the Blake Ridge gas hydrate province including drill Site locations of Ocean Drilling Program (ODP) Leg 164 (modified after Dillon and Paull [39]). Bathymetry contours are presented in meters. The shaded area (in pink) depicts the BSR occurrence.

Based on the $\mathrm{SO}_{4}$ profiles, it was postulated that anaerobic oxidation of methane (AOM) is the main process responsible for sulfate depletion at the Blake Ridge province [33]. The boundaries of the sulfate-presence-zone range from the seafloor to $\sim 20 \mathrm{mbsf}$ or $\sim 23 \mathrm{mbsf}$ and appears to be primarily controlled by the flux of methane from underlying sediments rather than organic matter supply from the top [33]. Gas hydrate deposits at the Blake Ridge province are mainly represented by structure I hydrates with $94 \%$ cage occupancy and volumetric gas to water ratio of $\sim 204$, which corresponds to a hydration number of $n=6.1$ calculated for in-situ pressure conditions at the Blake Ridge. Table 1 contains the general characteristics of Site 997, which has been chosen as a benchmark site for this numerical study. Data included in Table 1 were previously established from drilling reports, seismic data interpretations, and other sources.

Table 1. Blake Ridge Site 997 characterization.

\begin{tabular}{ccc}
\hline Parameter & Value & References \\
\hline Water depth & $2781 \mathrm{~m}$ & {$[20,33]$} \\
Bottom water temperature & $3.4^{\circ} \mathrm{C}$ & {$[20]$} \\
Geothermal gradient & $0.035^{\circ} \mathrm{C} \cdot \mathrm{m}^{-1}$ & {$[20]$} \\
Salinity & $35 \mathrm{PSU}$ & {$[20]$} \\
Gas composition & $99 \% \mathrm{CH}_{4}, 1 \% \mathrm{CO}_{2}\left(\right.$ here assumed $\left.100 \% \mathrm{CH}_{4}\right)$ & {$[38]$} \\
Seafloor porosity & 0.7 & Curve fitting parameter \\
Compaction length scale & $0.75 \times 10^{-3} \mathrm{~m}^{-1}$ & Curve fitting parameter \\
Organic carbon available at the seafloor & $1.6 \mathrm{wt} \%$ & {$[20,33]$} \\
\hline
\end{tabular}


To understand the depositional history at the Blake Ridge province, detailed studies on nannofossils and sedimentary particles have been performed [37]. According to the authors, productivity regimes at the Blake Ridge Site 997 can be divided into five distinct stages: Low-productivity stage 1 from 6.6 Ma to $6 \mathrm{Ma}$, high-productivity stage 2 from $6 \mathrm{Ma}$ to $4.8 \mathrm{Ma}$, low-productivity stage 3 from $4.8 \mathrm{Ma}$ to 3.6 Ma, fluctuating productivity stage 4 from $3.6 \mathrm{Ma}$ to $0.8 \mathrm{Ma}$, and the final low-productivity stage 5 from 0.8 Ma to present. These data imply a down-core increase in sedimentation rates (see Table 2), which has been used as an input dataset for our modeling runs.

Table 2. Rates of sediment accumulation at Blake Ridge Site 997 after Ikeda et al. [37].

\begin{tabular}{|c|c|c|c|}
\hline Epoch & Age (Ma) & Value $\left(\mathrm{mm} \cdot \mathrm{yr}^{-1}\right)$ & Sediment Depth after Compaction (mbsf) \\
\hline \multirow{3}{*}{ Pleistocene } & $0-0.53$ & 0.235 & $0-18$ \\
\hline & $0.53-1.26$ & 0.105 & $18-48$ \\
\hline & $1.26-1.65$ & 0.220 & $48-70$ \\
\hline \multirow{7}{*}{ Pliocene } & $1.65-2.51$ & 0.140 & $70-110$ \\
\hline & $2.51-2.55$ & 0.010 & 110-118 \\
\hline & $2.55-2.76$ & 0.145 & $118-151$ \\
\hline & $2.76-3.62$ & 0.180 & $151-308$ \\
\hline & $3.62-3.72$ & 0.155 & $308-324$ \\
\hline & $3.72-4.43$ & 0.205 & $324-339$ \\
\hline & $4.43-4.97$ & 0.055 & $339-415$ \\
\hline \multirow{3}{*}{ Late Miocene } & $4.97-5.59$ & $\sim 0.060$ & $415-552$ \\
\hline & $5.59-5.92$ & $\sim 0.005$ & $552-588$ \\
\hline & $5.92-6.6$ & $\sim 0.025$ & $588-750$ \\
\hline
\end{tabular}

\subsection{Depth Discrepancy between the Observed BSRs and the Base of the GHSZ at Sites 995 and 997}

A sharp BSR is present at a depth of $\sim 440-450$ mbsf at ODP drill Sites 995 and 997 [20]. The seismic signatures start to differ between the two Sites below the BSRs at depths between 440 and $530 \mathrm{mbsf}$, where the dipole waveform amplitudes have relatively high values at Site 977 and low values at Site 995, giving clear indications for differences in elastic properties [20]. Detailed analysis of a core from ODP Site 995 provide direct information on gas hydrate and free gas concentrations as well as a possible mixing zone of these two phases [21]. Indications for the presence of gas hydrates were found in the depth interval $200-440$ mbsf via core thermal measurements, chemical analysis, and sediment samples recovered using pressure core sampler (PCS) [20,40]. Moreover, high gradients in seismic $V_{p} / V_{s}$ wave speeds point to gradients in sediment consolidation possibly related to hydrate crystallization. A strong decrease in $V_{p}$ was found between depth of $\sim 440 \mathrm{mbsf}$ down to $\sim 520 \mathrm{mbsf}$, which is a good indication for the presence of free gas. However, it has been reported [21] that parallel to the $V_{p}$ decrease, no drop in $V_{p} / V_{s}$ was found, which was judged as unusual pointing to changes in mechanical properties. The authors discuss the possibility of gas hydrate dissociation over this interval to explain the differences in sediment consolidation with depth. The deepest analyzed section (> 520 mbsf) shows no hints for the presence of gas hydrates and is characterized by a significant decrease in $V_{p} / V_{s}$ consistent with the presence of free gas.

Contrary to the indirect observations, thermal and chemical analysis of the core from Site 995 did not indicate gas hydrate presence deeper than $\sim 440 \mathrm{mbsf}$. However, the base of the thermodynamic GHSZ (based on theoretical steady-state calculations) is deeper at $~ 540$ mbsf [21]. Several authors gave hypothetic explanations for this GHSZ thickness discrepancy suggesting that strong capillary forces arising in the fine-grained sediments might move the BSR up [41,42]. As a consequence of the developing capillary forces, gas hydrate may preferentially dissociate in the smaller sediment pores, which would allow for the co-existence of free methane gas and gas hydrates in bigger sediment pores.

Gas hydrates were present in the Site 997 core at depths from 180 to $240 \mathrm{mbsf}$ and from 380 to $\sim 450 \mathrm{mbsf}[20,24]$. Hydrate concentrations estimated from the ODP drilling results are relatively low at $\sim 4 \%-7 \%[20,27]$ and an external upward fluid flow of approximately $0.2 \mathrm{~mm} \cdot \mathrm{year}^{-1}$ was 
inferred [27] based on measured $\mathrm{Br}^{-} / \mathrm{I}^{-}$ions ratios. However, the above estimates on gas hydrate saturation are based on indirect methods (e.g., chlorinity and salinity measurements) and remain debatable. Thickness of the thermodynamic GHSZ extends to $\sim 500 \mathrm{mbsf}$ and does not match the depth of the BSR ( 450 mbsf) [21]. A hypothesis of gas hydrate and free gas co-existence in the overlapping interval ( $450 \mathrm{mbsf}-500 \mathrm{mbsf}$ ) might be applicable to this site with some additional comments: As it was reported by Guerin et al. [21], only a $40 \mathrm{~m}$ thick interval below $450 \mathrm{mbsf}$ has some indications for free gas presence. Monopole waveforms of the deeper part of this section remain not attenuated. Therefore, the discrepancy between observed BSR depth and theoretical GHSZ suggests a non-steady state situation.

\subsection{Previous Modeling Approaches of the Blake Ridge Site 997}

Previous modeling attempts to investigate the dynamics of gas hydrate formation at Blake Ridge Site 997 have been conducted by several authors [25,26,29-31,43]. The potential of gas hydrate crystallization and distribution was investigated [29] for diffusion versus advection-dominated systems using a steady-state analytical model. According to these findings, a sufficiently high methane mass flux of about $3 \times 10^{-11} \mathrm{~kg} \mathrm{~s}^{-1} \mathrm{~m}^{-2}$ at the bottom of the GHSZ is required for hydrate accumulations to extend down to the base of the theoretical GHSZ [29]. In that case, a quasi-steady state was obtained after 10 Myr simulation time. They concluded that the observed surface POC fraction of $1.5 \mathrm{wt} . \%$ results in an average hydrate fraction of about $2 \mathrm{vol} . \%$, which is lower than the inferred gas hydrate concentrations (4 vol.\%-7 vol.\% after Paull et al. [20]). Thus, a significant methane supply from underlying sediments was required to match the field observations. The dynamics of gas hydrate formation were investigated $[30,31]$ in terms of (1) a constant upward fluid velocity of about $0.26 \mathrm{~mm}$ year $^{-1}$ and (2) fluid flow restricted to $0.08 \mathrm{~mm}_{\text {year }}{ }^{-1}$ and in-situ biogenic methane source with $50 \%$ conversion of the available organic carbon. This numerical approach did not contain a bacterial sulfate reduction zone. The first scenario resulted in 3 vol. $\%$ of gas hydrates and 2 vol. $\%$ of free gas occupying the pore space, whereas the second one led to 5 vol.\% and 3 vol.\% of gas hydrates and free gas, respectively. Integrating AOM reaction into the model [31] showed that a good fit of modeled sulfate curves occurs for the first scenario assuming a high upward flux of the fluid phase. Although it has been concluded that the anaerobic oxidation of methane is the dominant reaction leading to sulfate depletion at the Blake Ridge Site, it was apparently difficult to obtain a fit between model predictions and observed chloride and sulfate concentrations. A complex study on gas hydrate dynamics at the Blake Ridge Site was conducted [26] incorporating the entire biogeochemical datasets of dissolved bromide, ammonium, iodide, sulfate, total nitrogen, and organic carbon available at the seafloor. Moreover, this modeling approach contained a novel reaction rate for in-situ biogenic methane formation that links the concentration of degradable organic carbon to the concentration of dissolved methane and inorganic carbon via Monod inhibition rates and age-dependent kinetics. POC concentration at the seafloor were kept constant (1.6 wt.\%) for the first period of $5 \mathrm{Myr}$ and then, subsequently, lowered to $0.65 \mathrm{wt} . \%$ for the last $0.7 \mathrm{Myr}$. The best fit to the geochemical profiles was obtained for interstitial fluid velocities of $0.12 \mathrm{~mm}_{\text {year }}{ }^{-1}$ calculated at the sediment surface and assuming an additional low upward fluid flux at the base of the model. However, gas hydrate concentrations obtained in this case were one order of magnitude lower (about 0.6 vol.\%) than observed at that site. Presence of gas bubbles ascending from the deep origin has been proposed as an explanation for higher hydrate concentrations reported from the field. A series of modeling scenarios for a Blake Ridge Site were presented [25] including only in-situ methane generation, prescribed flux of dissolved methane through a lower boundary (fluid mass of $9 \times 10^{-9} \mathrm{~kg} \mathrm{~s}^{-1} \mathrm{~m}^{-2}$ ), or a mixed methane source (in-situ generation plus $40 \%$ of previous fluid mass flux). It was concluded that in-situ methane generation alone does not explain gas hydrate concentrations observed in the Blake Ridge and, moreover, an upward fluid flux applied in the second scenario corresponds to the seafloor fluid velocities of about $0.28 \mathrm{~mm} \mathrm{year}^{-1}$, which remains too high in comparison to the deduced interstitial fluid velocities [27]. The third modeling scenario assuming mixed methane source stays in good agreement with reported seafloor velocities 
and the average gas hydrate concentrations obtained in this case are about 5 vol. $\%$, however free gas concentrations not exceeding 3 vol. $\%-4$ vol. $\%$ seem to be too low with respect to the observations.

\section{Materials and Methods}

\subsection{Mathematical Model}

\subsubsection{Introduction}

The new numerical multi-phase model simulates gas hydrate and free gas formation from both in-situ POC degradation and a deeply sourced methane flux. The model contains four phases (solid porous matrix, pore fluids, gas hydrate, and gaseous methane $\left.\left(\mathrm{CH}_{4}{ }^{\text {gas }}\right)\right)$ and four chemical species (organic carbon (POC), dissolved inorganic carbon (DIC diss), dissolved methane $\left(\mathrm{CH}_{4}{ }^{\text {diss }}\right)$, dissolved sulfates $\left.\left(\mathrm{SO}_{4}{ }^{\text {diss }}\right)\right)$. The model resolves four key bio-chemical processes in anoxic marine sediments: (1) POC degradation, (2) sulfate reduction, (3) methanogenesis, and (4) anaerobic oxidation of methane (AOM). Sediment pore space can be occupied by three phases (pore fluids carrying chemical species, solid gas hydrates, and free methane gas). Gas hydrate present in the pore space is assumed stationary with respect to the grains and is transported with the burial velocity of sediments. Formation of gas hydrate and free gas takes place whenever the concentration of dissolved methane exceeds the solubility limit [44]. Gas hydrate and free gas formation is assumed to occur under equilibrium thermodynamic equilibrium, which leads to an assumption that only two phases can occupy the pore space at the same time (fluids and gas hydrates or fluids and free gas).

\subsubsection{Governing Equations}

Water and methane components included in the model can occur in different phases: Solid (gas hydrate), fluid (brine, dissolved methane), and gaseous (free methane). We assume that sediment pores are always fully saturated with fluid, gas, and gas hydrates $\left(S_{f}+S_{g}+S_{h}=1\right)$.

Sediment grains, gas hydrate, and organic carbon (POC) are transported downward according to the solid burial velocity and Equations (1) and (2) describe the mass balance formulation for solid sediment grains and gas hydrates, respectively:

$$
\frac{\partial\left((1-\phi) \rho_{s}\right)}{\partial t}=-\nabla \cdot\left((1-\phi) \rho_{s} \vec{V}_{s}\right)
$$

where $\phi$ - porosity, $\rho_{s}$-density of sediment grains, $V_{s}$ - burial velocity of solids, $t$ - time.

$$
\frac{\partial\left(\phi S_{h} \rho_{h}\right)}{\partial t}=-\nabla \cdot\left(\phi S_{h} \rho_{h} \vec{V}_{s}\right)+Q_{h}
$$

where $S_{h}$-hydrate saturation, $\rho_{h}$-density of hydrate, $Q_{h}$ - source term accounting for hydrate precipitation and dissolution.

Mass conservation of fluid and gas phase is presented as Equations (3) and (4), respectively.

$$
\frac{\partial\left(\phi S_{f} \rho_{f}\right)}{\partial t}=-\nabla \cdot\left(\phi S_{f} \rho_{f} \vec{V}_{f}\right)
$$

where $S_{f}$ fluid phase saturation, $\rho_{f}$-density of fluid, $V_{f}$-fluid phase velocity.

$$
\frac{\partial\left(\phi S_{g} \rho_{g}\right)}{\partial t}=-\nabla \cdot\left(\phi S_{g} \rho_{g} \vec{V}_{g}\right)+Q_{g}
$$

where $S_{g}$ —gas phase saturation, $\rho_{g}$ —density of gas, $V_{g}$ —gas phase velocity, $Q_{g}$ — source term accounting for free gas formation and dissolution. 
Gas hydrates are advected with a solid velocity $\left(V_{s)}\right.$ according to the rate of sediment burial and compaction. Fluid $\left(V_{f}\right)$ and gas $\left(V_{g}\right)$ velocities are derived from the Darcy' formulation and are shown in the Equations (5) and (6), respectively:

Darcy' velocity for fluids:

$$
\vec{U}_{f}=\phi S_{f}\left(\vec{V}_{f}-\vec{V}_{s}\right)=-\frac{k k_{r}^{f}}{\mu_{f}}\left(\nabla P-\rho_{f} \vec{g}\right)
$$

where $k$-intrinsic permeability, $k_{r}$-fluid relative permeability, $\mu_{f}$-fluid viscosity, $d P$ —pressure gradient, $g$-gravitational acceleration.

Darcy' velocity for gas:

$$
\vec{U}_{g}=\phi S_{g}\left(\vec{V}_{g}-\vec{V}_{s}\right)=-\frac{k k_{r}^{g}}{\mu_{g}}\left(\nabla P-\rho_{g} \vec{g}\right)
$$

where $k_{r}^{g}$-gas relative permeability, $\mu_{g}$ —gas viscosity.

The dynamic viscosities $\mu_{f}$ (fluid phase) and $\mu_{g}$ (gas phase) from Equations (5) and (6) are represented by constant values valid over the investigated pressure and temperature ranges (see Table 3).

\begin{tabular}{|c|c|c|c|}
\hline Parameter & Symbol & Value & References \\
\hline Gravitational acceleration & $g$ & $9.81 \mathrm{~m} \cdot \mathrm{s}^{-2}$ & - \\
\hline Density of sediment grains & $\rho_{s}$ & $2650 \mathrm{~kg} \cdot \mathrm{m}^{3}$ & - \\
\hline Density of gas hydrate & $\rho_{h}$ & $913 \mathrm{~kg} \cdot \mathrm{m}^{3}$ & - \\
\hline Intrinsic permeability & $k$ & Equation (7) & [45] \\
\hline Geometrical factor & $B$ & 0.5 & [45] \\
\hline Specific surface area & $S$ & $10^{7} \mathrm{~m}^{2} / \mathrm{m}^{3}$ & [45] \\
\hline Relative permeability of fluid & $k_{r}^{f}$ & Equation (8) & [46] \\
\hline Relative permeability of gas & $k_{r}^{g}$ & Equation (9) & [46] \\
\hline Dynamic viscosity of fluid & $\mu_{f}$ & $10^{-3} \mathrm{~Pa} \cdot \mathrm{s}$ & [47] \\
\hline Dynamic viscosity of gas & $\mu_{g}$ & $11.5 \times 10^{-6} \mathrm{~Pa} \cdot \mathrm{s}$ & [48] \\
\hline Sediment factor & $m$ & 0.197 & [49] \\
\hline Residual water saturation & $S_{r f}$ & 0.03 & [49] \\
\hline Residual gas saturation & $S_{r g}$ & $0.05-0.1$ & This study \\
\hline Compressibility of fluid & $\beta_{f}^{\circ}$ & $4 \times 10^{-10} \mathrm{~Pa}^{-1}$ & [45] \\
\hline Compressibility of gas & $\beta_{g}$ & $10^{-7} \mathrm{~Pa}^{-1}$ & [45] \\
\hline Compressibility of hydrate & $\begin{array}{l}\beta_{8} \\
\beta_{h}\end{array}$ & $10^{-15} \mathrm{~Pa}^{-1}$ & {$[50]$} \\
\hline Thermal conductivity of solids & $\lambda_{s}$ & $2.4 \mathrm{~W} \cdot \mathrm{m}^{-1} \cdot \mathrm{K}^{-1}$ & [45] \\
\hline Thermal conductivity of fluid & $\lambda_{f}$ & $0.6 \mathrm{~W} \cdot \mathrm{m}^{-1} \cdot \mathrm{K}^{-1}$ & {$[45]$} \\
\hline Thermal conductivity of gas & $\lambda_{g}$ & $1 \mathrm{~W} \cdot \mathrm{m}^{-1} \cdot \mathrm{K}^{-1}$ & [45] \\
\hline Thermal conductivity of hydrate & $\lambda_{h}$ & $0.50 \mathrm{~W} \cdot \mathrm{m}^{-1} \cdot \mathrm{K}^{-1}$ & [51] \\
\hline Specific heat capacity of solids & $C_{p s}$ & $835 \mathrm{~J} \cdot \mathrm{kg}^{-1} \cdot \mathrm{K}^{-1}$ & [45] \\
\hline Specific heat capacity of fluid & $C_{p f}$ & $\begin{array}{c}4181.3 \\
\mathrm{I} \cdot \mathrm{kg}^{-1} \cdot \mathrm{K}^{-1}\end{array}$ & [45] \\
\hline Specific heat capacity of gas & $C_{p g}$ & $2200 \mathrm{~J} \cdot \mathrm{kg}^{-1} \cdot \mathrm{K}^{-1}$ & [45] \\
\hline Specific heat capacity of hydrate & $C_{p h}$ & $1650 \mathrm{~J} \cdot \mathrm{kg}^{-1} \cdot \mathrm{K}^{-1}$ & [52] \\
\hline
\end{tabular}

Table 3. Physical parameters used in numerical simulations (see further description in text).

The intrinsic permeability can be derived from a Kozeny-Carman-type relationship defined according to Equation (7) [45]. Parameters $S$ and $B$ included in Equation (7) represent scaling factors valid for various lithologies (see Table 3 for exact values used in the model). If hydrates are present within the pore space, additional scaling of the intrinsic permeability is required. Thus, effective 
porosity and effective tortuosity should be introduced in the Equation (7) as $\phi_{\text {eff }}=\phi \times\left(1-S_{h}\right)$ and $T_{o_{-} \text {eff }}=1-\log \left(\phi_{\text {eff }}\right)$.

$$
k=\frac{B \cdot \phi^{3}}{T_{0}^{2} \cdot S^{2}}
$$

where $B$-geometrical factor, $T_{0}$-tortuosity, $S$-specific surface area.

In a case of a multiphase flow, the relative permeability of fluid $\left(k_{r}{ }^{f}\right)$ and methane gas $\left(k_{r}{ }^{g}\right)$ phases are defined as follows [46]:

$$
k_{r}^{f}=\left(\min \left(\frac{S_{f}-S_{r f}}{1-S_{r f}-S_{r g}}, 1\right)\right)^{1 / 2} \cdot\left(1-\left(1-\left(\min \left(\frac{S_{f}-S_{r f}}{1-S_{r f}-S_{r g}}, 1\right)\right)^{1 / m}\right)^{m}\right)^{2}
$$

where $S_{r f}$-residual saturation of fluid, $m$ —sediment factor.

$$
k_{r}^{g}=\left(1-\min \left(\frac{S_{f}-S_{r f}}{1-S_{r f}-S_{r g}}, 1\right)\right)^{1 / 2} \cdot\left(1-\min \left(\frac{S_{f}-S_{r f}}{1-S_{r f}-S_{r g}}, 1\right)^{1 / m}\right)^{2 m}
$$

where $S_{r g}$-residual saturation of gas.

The sediment factor $\mathrm{m}$ (Equations (8) and (9)) varies with lithology (see Table 3). The residual fluid $\left(S_{r f}\right)$ and residual gas $\left(S_{r g}\right)$ saturations describe the immobile fraction of each phase (see Table 3$)$. The minimum condition (Min) is introduced to maintain the relative gas permeability $\left(k_{r}{ }^{g}\right)$ at zero for gas saturations below the residual value $S_{r g}$. The exact amount of gas that represents the residual immobile fraction is still under discussion. $S_{r g}$ is believed to have very small values during drainage processes (from 0 to 0.02 ). Thus, only a small fraction of the upward migrating gas is trapped when gas invaded fluid-filled pores. The hysteresis that occurs during alternating drainage as well as the wetting cycles are not considered in the model since our focus is essentially limited to drainage processes. We found it convenient to use $S_{r g}=0.05-0.1$ to describe the gas flow reported from naturally occurring gas hydrate provinces (see Table 3).

The pore pressure has been calculated according to Equation (10), where $i$ denotes fluid, free gas, and hydrate phases and $j$ stands for fluid and gas phase only:

$$
\sum_{i}\left[\phi S_{i} \frac{D \rho_{i}}{D t}\right]=\sum_{j}\left[\nabla \cdot\left(\frac{k k_{r}^{j}}{\mu_{j}} \rho_{j}\left(\nabla P+\rho_{j} \vec{g}\right)\right)\right]-\sum_{i}\left[-S_{i} \rho_{i} \frac{1}{(1-\phi)} \frac{D \phi}{D t}+\frac{\phi \rho_{i} S_{i}}{\rho_{s}} \frac{D \rho_{s}}{D t}\right]
$$

where $S_{i}$-saturation of a given phase, $\rho_{i}$-density of a given phase, $k_{r}{ }^{j}$-relative permeability of a given phase, $\mu_{j}$-viscosity of a given phase, $D$-material (substantial) derivative defined as:

$$
\frac{D}{D t}=\frac{\partial}{\partial t}+\vec{V}_{s} \cdot \nabla
$$

Material derivative (Equation (11)) is commonly used to describe the rate of change of a physical property (e.g., density in Equation (10)) along a solid-flow streamline. The choice of the reference frame used in the model implies that all the material derivatives turns into the normal derivatives due to the fact that the motion of sediment grains $\left(V_{s}\right.$ from Equation (11)) is accounted for by adjusting the reference frame. The LHS of the Equation (10) accounts for a density change of fluid, gas, and hydrate phase with time. The first term on the RHS accounts for fluid and gas flow. The second term on the RHS describes mechanical sediment compaction and changes in solid density. The values of compressibility factors for fluid, gas, and gas hydrate phases introduced during the Equation (10) derivation $\left(\beta_{f}, \beta_{g}\right.$, and $\beta_{h}$, respectively) are listed in Table 3. 
Equation (12) shows the general mass balance equation for chemical species dissolved in pore fluids, which is a function of advective and diffusive transport as well as a source term:

$$
\frac{\partial\left(\phi S_{f} C\right)}{\partial t}=\nabla \cdot\left(\phi S_{f} D \nabla C\right)-\nabla \cdot\left(\phi S_{f} C \vec{V}_{f}\right)+Q_{f}
$$

where $C$-concentration of chemical species dissolved in pore fluids, $D$-diffusion coefficient, $Q_{f}$ - source term accounting for bio-chemical reactions occurring in the fluid phase, and $t$-time.

The rate of molecular diffusion in marine sediments depends on temperature and salinity conditions. Molecular diffusion coefficients $\left(D_{m}\right)$ of chemical species dissolved in pore fluids $\left(\mathrm{CH}_{4}\right.$, $\mathrm{SO}_{4}$, and DIC) are calculated according to formulations from Boudreau [53]. The effect of tortuosity has been considered by applying the Archie's law and calculating the diffusion coefficients in sediments $\left(D_{s}\right)$. Diffusive transport of DIC is calculated as a mixture (1:1) of two major DIC species: $\mathrm{HCO}_{3}$ and $\mathrm{CO}_{2}$ that are widely present at the anoxic, near-neutral $\mathrm{pH}$ conditions.

The source term $Q_{f}$ in the above mass balance equation accounts for all additional chemical species supply as a result of bio-chemical reaction rates, such as AOM, sulfate reduction, and methanogenesis. Further description of these processes can be found in the following Section 2.1.3.

\subsubsection{Source Terms-Bio-Chemical Reactions}

The rate of POC degradation greatly influences the amount of gas hydrate formed within the GHSZ [16]. A large amount of globally observed gas hydrate accumulations was formed due to anaerobic decay of a deeply buried organic matter $[12,16]$. However, only a relatively small fraction of the POC deposited at the seafloor is transported to a certain depth below the bioturbated surface layer of sediments. According to Flogel et al. [54], about 10\% of the deposited POC is buried below $10 \mathrm{~cm}$ sediment depth at continental margins while only about $1 \%$ of POC passes by the bioturbated zone of the first $10 \mathrm{~cm}$ of sediments in pelagic deep-ocean environments, which partially explains the lack of gas hydrate deposits in the latter case.

In our model, the rate of organic carbon degradation follows the approach from Middelburg [55] modified by Wallmann et al. [26], which assumes an age-decreasing reactivity of POC according to the following Equation (13):

$$
R_{P O C}=\frac{K_{c}}{C(D I C)+C\left(\mathrm{CH}_{4}\right)+K_{c}} \cdot k_{x} \cdot G(P O C)
$$

where $R_{P O C}$ is the rate of organic carbon degradation, $C(D I C)$ - concentration of dissolved inorganic carbon, $\mathrm{C}\left(\mathrm{CH}_{4}\right)$ - concentration of dissolved methane, $\mathrm{G}(\mathrm{POC})$-concentration of solid POC fraction, $K_{c}-$ Monod inhibition constant, $k_{x}$-age-dependent kinetic constant.

The age-dependent kinetic constant $k_{x}$ is calculated according to the following expression [55]:

$$
k_{x}=0.16 \cdot\left(a_{0}+\frac{z}{\vec{V}_{s}}\right)^{-0.95}
$$

where $a_{0}$-the initial age of organic matter decay (entering the methanogenic zone).

Furthermore, methanogenesis is inhibited in the presence of sulfate such that methane generation occurs only after dissolved sulfate has been depleted by microbial sulfate reduction and AOM [26]. The resulting rates of methane generation and oxidation are applied as source term $Q$ in the mass balance equation for methane (Equation (11)) to quantify the supply of $\mathrm{CH}_{4}$ into the system as a result of above microbial reactions. The full compilation of modeling parameters considering POC degradation and AOM processes at the Blake Ridge Site 997 is presented in Table 4. 
Table 4. Geochemical parameters used in numerical modeling scenarios for Site 997 (see further description in text).

\begin{tabular}{|c|c|c|c|}
\hline Parameter & Symbol & Value & References \\
\hline Initial age of organic matter decomposition & $a_{0}$ & $5 \times 10^{5}$ years & {$[26]$} \\
\hline $\begin{array}{c}\text { Monod inhibition constant of organic matter } \\
\text { degradation } \\
\text { by DIC and } \mathrm{CH}_{4}\end{array}$ & $K_{c}$ & $40 \mathrm{mM}$ & [26] \\
\hline Monod inhibition constant of $\mathrm{CH}_{4}$ formation by $\mathrm{SO}_{4}$ & $K_{S O 4}$ & $1 \mathrm{mM}$ & [26] \\
\hline Kinetic constant for AOM & $k_{A O M}$ & $1 \mathrm{~cm}^{3} \cdot$ year $^{-1} \cdot \mathrm{mmol}^{-1}$ & {$[26]$} \\
\hline Sulfate concentration at the upper model boundary & $\mathrm{C}_{\mathrm{SO} 4}$ & $28 \mathrm{mM}$ & [20] \\
\hline Methane concentration at the upper boundary & $\mathrm{C}_{\mathrm{CH} 4}$ & $10^{-4} \mathrm{mM}$ & [26] \\
\hline $\begin{array}{c}\text { Dissolved Inorganic Carbon (DIC) concentration } \\
\text { at the upper boundary }\end{array}$ & $C_{D I C}$ & $4 \mathrm{mM}$ & [26] \\
\hline
\end{tabular}

In the model, density of pore fluids occupying the pore space of sediments depends on temperature, pressure, salt content, and dissolved methane. To calculate the density of a $\mathrm{H}_{2} \mathrm{O}-\mathrm{NaCl}$ mixture, we have used a numerical toolbox for Matlab [56]. Density of a $\mathrm{H}_{2} \mathrm{O}-\mathrm{NaCl}-\mathrm{CH}_{4}$ mixture was calculated from the equation-of-state derived by Duan et al. [57]. Methane gas density, methane gas solubility, and gas hydrate solubility are calculated as time-dependent variables according to the equations from Tishchenko et al. [44] and Duan et al. [57], which include the effect of salinity.

\subsubsection{Temperature}

The temperature field is calculated according to Equation (15) assuming a constant heat flux at the bottom of a modeling domain $\left(\mathrm{z}_{\max }(\mathrm{t})\right)$ and a fixed temperature value at the sea-surface $(\mathrm{z}=0)$ :

$$
\left(\rho C_{p}\right)_{b u l k} \frac{\partial T}{\partial t}=-\left(\rho C_{p}\right)_{b u l k} \vec{V}_{s} \cdot \nabla T-\rho_{f} C_{p_{f}} \vec{U}_{f} \cdot \nabla T-\rho_{g} C_{p_{g}} \vec{U}_{g} \cdot \nabla T+\nabla \cdot\left(\lambda_{b u l k} \nabla T\right)+Q
$$

where $T$-temperature, $\left(\rho C_{p}\right)_{\text {bulk }}$-volumetric heat capacity, $C_{p f}$ - heat capacity of fluid phase, $C_{p g}$ - heat capacity of gas phase, $\lambda_{b u l k}$-bulk thermal conductivity, $Q$-latent heat from melting hydrates.

Bulk volumetric heat capacity accounts for all phases present in the model according to their saturations, which contribute to the total energy balance:

$$
\left(\rho C_{p}\right)_{b u l k}=(1-\phi) \rho_{s} C_{p_{s}}+\phi S_{f} \rho_{f} C_{p_{f}}+\phi S_{g} \rho_{g} C_{p_{g}}+\phi S_{h} \rho_{h} C_{p_{h}}
$$

where $C_{p h}$-heat capacity of hydrate phase.

According to Deming and Chapman [58], bulk thermal conductivity can be expressed as:

$$
\lambda_{\text {bulk }}=\lambda_{s}^{(1-\phi)} \lambda_{f}^{\phi}
$$

where $\lambda_{s}$-thermal conductivity of solid phase, $\lambda_{f}$-thermal conductivity of fluid phase.

However, in the four-phase system, we have to include another two terms accounting for hydrate and free gas components [59]:

$$
\lambda_{\text {bulk }}=\lambda_{s}^{(1-\phi)} \lambda_{f}{ }^{S_{f} \phi} \lambda_{g}{ }^{S_{g} \phi} \lambda_{h}{ }^{S_{h} \phi}
$$

where $\lambda_{g}$-thermal conductivity of gas phase, $\lambda_{h}$-thermal conductivity of hydrate phase.

According to Waite et al. [59], in porous ( $>30 \%$ ) sediments filled in by at least $10 \%$ hydrates, gas hydrate contribution to the bulk thermal conductivity increases significantly. We found the number of $0.65 \mathrm{~W} \cdot \mathrm{m}^{-1} \cdot \mathrm{K}^{-1}$ accounting for the thermal conductivity of gas hydrate convenient and used this constant value in our simulations. Latent heat from gas hydrate dissociation (term $Q$ in Equation (14)) has a constant value of $450 \mathrm{~kJ} \mathrm{~kg}^{-1}$ (equivalent to $53.8 \mathrm{~kJ} \mathrm{~mol}^{-1}$ ) as it was previously reported [25]. 


\subsection{Numerical Model}

\subsubsection{Reference Frame}

We use a reference frame that is attached to the seafloor. During each time step, sediments are deposited according to a prescribed rate. Subsequently, compaction occurs and the seafloor is adjusted back to zero by shifting the entire sediment package downwards. This approach allows for the variable deposition of different rock types through time, and a schematic visualization of the reference frame concept is shown in Figure 2.

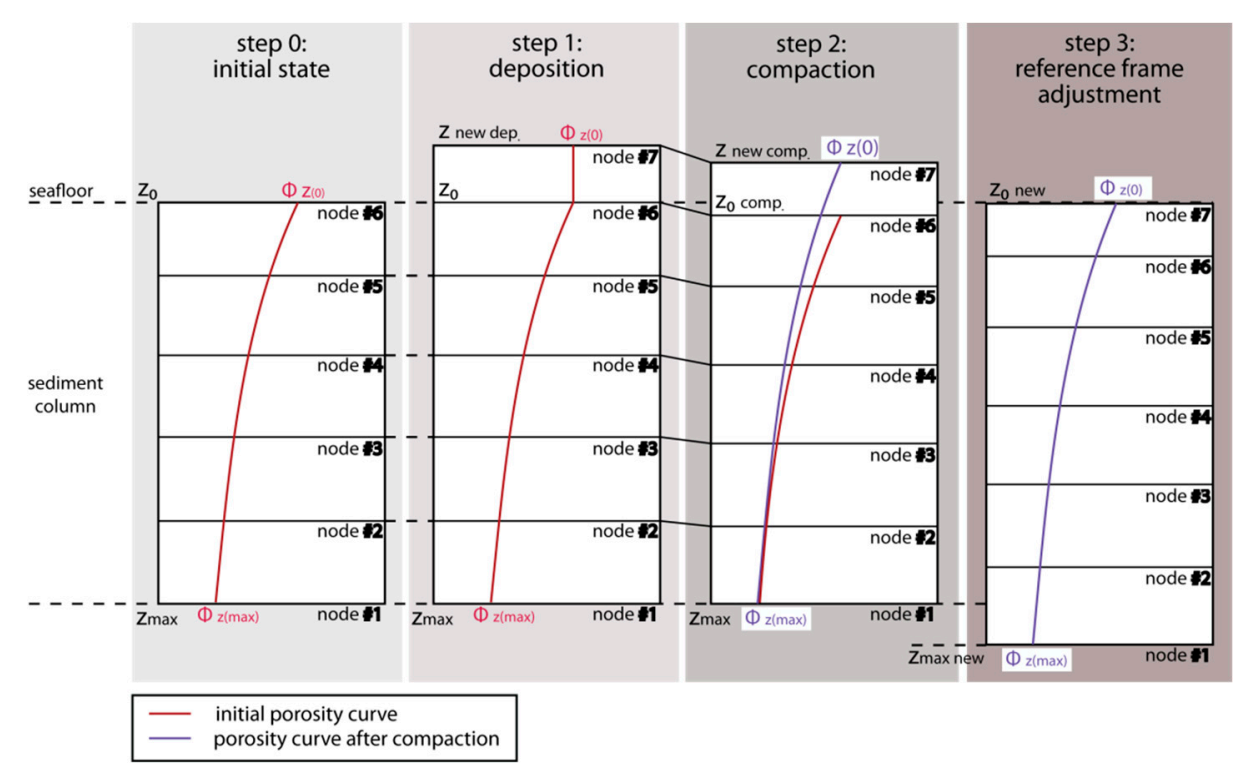

Figure 2. Schematic illustration of the reference frame concept used in the model previously validated by Schmidt et al. [60]. Starting from the left: Step 0 represents the initial state of modeled sedimentary column extending from the seafloor $\left(\mathrm{z}_{0}\right)$ to the maximum sediment depth $\left(\mathrm{z}_{\max }\right)$ with an initial porosity curve (red line) ranging from high seafloor porosity value $\left(\Phi_{z(0)}\right)$ up to low maximum sediment depth value $\left(\Phi_{z(\max )}\right)$ containing an initial number of nodes in the z-direction. In step 1, a new sedimentary layer, represented by the node \#7, has been deposited on top of the existing column. The top of the new layer has been marked by the $z_{n e w}$ dep. symbol and porosity of the new layer remains constant with depth. Step 2 depicts a compaction process of all deposited layers according to their lithological properties (in the drawing assumed to be homogeneous for simplicity) and a new porosity curve (violet line) as a result of this process. Finally, step 3 shows a vertical adjustment of the reference frame to match the upper boundary of sedimentary column with the seafloor coordinates $\mathrm{z}_{0}$ and a new porosity curve (violet line). Note that porosity curves, including initial (seafloor) porosity values, are only symbolic and do not represent the real compaction properties of the Blake Ridge sediments.

Sediment compaction occurs according to a depth-dependent parametrization of porosity (Equation (19)).

$$
\phi_{(z)}=\phi_{(0)} \cdot \exp \left(c_{0} \cdot z\right)
$$

where $\phi_{(z)}$-porosity change with depth, $\phi_{(0)}$-initial porosity on top of a sediment layer, $z$-depth, $c_{0}$-the compaction length scale of a given lithology.

As sediment consolidation drives fluid flow and thereby reactive-transport within the sediment column, variations in sediment type and associated compaction behavior can potentially have a significant influence on pore fluid chemistry-an effect that our model allows us to investigate.

In general, methane supply to the GHSZ can occur via three distinct processes: In-situ $\mathrm{CH}_{4}$ formation within stability zone, advective fluid transport from below, or by rising free gas. In the simple case of in-situ methane generation, no flux boundary conditions are prescribed at the bottom of 
the modeling column. Fluids expelled by sediment compaction move upwards with respect to the sediment grains. However, due to the deposition of new sedimentary layers, expelled pore fluids never reach the seafloor. In the case of a prescribed fluid flux at the base, two additional scenarios of fluid migration are possible: (1) Either the rate of fluid influx is sufficiently high to overcome the burial velocity so that fluid venting occurs at the seafloor, or (2) burial continues to dominate and the increase in upward fluid flux continues to be insufficient for seafloor venting to occur.

\subsubsection{Initial and Boundary Conditions}

At the beginning of each run, constant concentrations of dissolved $\mathrm{CH}_{4}, \mathrm{SO}_{4}$, and DIC are prescribed at the top of the modeling column according to the values given in Table 4. Additionally, sulfate concentration profile at the beginning of each model run is initialized to decrease exponentially with depth. Concentration of POC (wt.\%) at the top of sediment column is set to $1.6 \mathrm{wt} . \%$ (see Table 1) and stays constant (Scenarios 1-2, and 4) or decreases with time (Scenarios 3 and 5). Salinity of pore fluids is assumed to be constant (see Table 1). To initialize the P-T conditions, we use a hydrostatic pressure that accounts for $\mathrm{NaCl}$ and $\mathrm{CH}_{4}$-dependent fluid density, constant bottom water temperature, and a steady-state geotherm to match the local measurements (see Table 1).

\subsubsection{Solution Algorithm}

Each computational step starts with the deposition of a new sedimentary layer according to the sedimentation rate and the time-step size $(d t)$. Next, compaction is accounted for and the top of the modeling domain is adjusted accordingly. The change in porosity is driving pore pressure, which is calculated using a finite elements (FE) scheme. Darcy velocity calculations for fluid and gas phase are based on the outcome of the pressure solver and relative permeability computation. At this stage, the Courant number is calculated, which limits the time-step in case of a Darcy flow exceeding the volume of one modeling cell. If the time-step needs to be reduced, the solution algorithm starts from the beginning, which implies that the pore pressure is computed again with a reduced $d t$. The temperature solver calculates the temperature profile for the entire sedimentary column. According to the temperature profile, diffusion coefficients for the dissolved chemical species are updated. Advection and diffusion calculations are split and solved separately for each phase using a finite volumes (FV) numerical approach. The last part of the numerical procedure contains computation of all bio-chemical reactions occurring in the system. Equation-of-state (EOS) for brine-gas-gas hydrate system is applied at the end to account for new saturations, densities, and volume changes of each phase. The model has been entirely implemented in Matlab v.2018.

\section{Results and Discussion}

To investigate gas hydrate formation from a single in-situ methane source as well as the possible impact of an upward fluid flux at the Blake Ridge Site, we have explored seven numerical modeling scenarios listed in Table 5. Detailed descriptions of each modeling scenario as well as the results are presented below.

Table 5. Summary of modeling scenarios presented in the study.

\begin{tabular}{ccccccccc}
\hline Scenario & $\mathbf{1}$ & $\mathbf{2 a}$ & $\mathbf{2 b}$ & $\mathbf{2 c}$ & $\mathbf{3}$ & $\mathbf{4}$ \\
\hline Sources of methane & $\begin{array}{c}\text { In-situ POC } \\
\text { degradation }\end{array}$ & $\begin{array}{c}\text { In-situ POC } \\
\text { degradation }\end{array}$ & $\begin{array}{c}\text { In-situ POC } \\
\text { degradation }\end{array}$ & $\begin{array}{c}\text { In-situ POC } \\
\text { degradation }\end{array}$ & $\begin{array}{c}\text { In-situ POC } \\
\text { degradation }\end{array}$ & $\begin{array}{c}\text { In-situ }+ \\
\text { Methane flux }\end{array}$ & $\begin{array}{c}\text { In-situ + } \\
\text { Methane flux }\end{array}$ \\
\hline Sedimentation rates & $22 \mathrm{~cm} \cdot \mathrm{kyr}^{-1}$ & Variable & Variable & Variable & Variable & Variable & Variable \\
\hline POC content at the seafloor & $1.6 \mathrm{wt} \%$ & $1.6 \mathrm{wt} \%$ & $1.6 \mathrm{wt} \%$ & $1.6 \mathrm{wt} \%$ & Variable & $1.6 \mathrm{wt} \%$ & Variable \\
\hline Diffusion of dissolved species & - & - & diminished & enhanced & - & - \\
\hline Simulation time & $10 \mathrm{Myr}$ & $10 \mathrm{Myr}$ & $10 \mathrm{Myr}$ & $10 \mathrm{Myr}$ & $10 \mathrm{Myr}$ & $10 \mathrm{Myr}$ & $10 \mathrm{Myr}$ \\
\hline Figure with the Results & Figure 3 & Figure 4 & Figure 5 & Figure 6 & Figure 7 & Figure 8 & Figure 9 \\
\hline
\end{tabular}



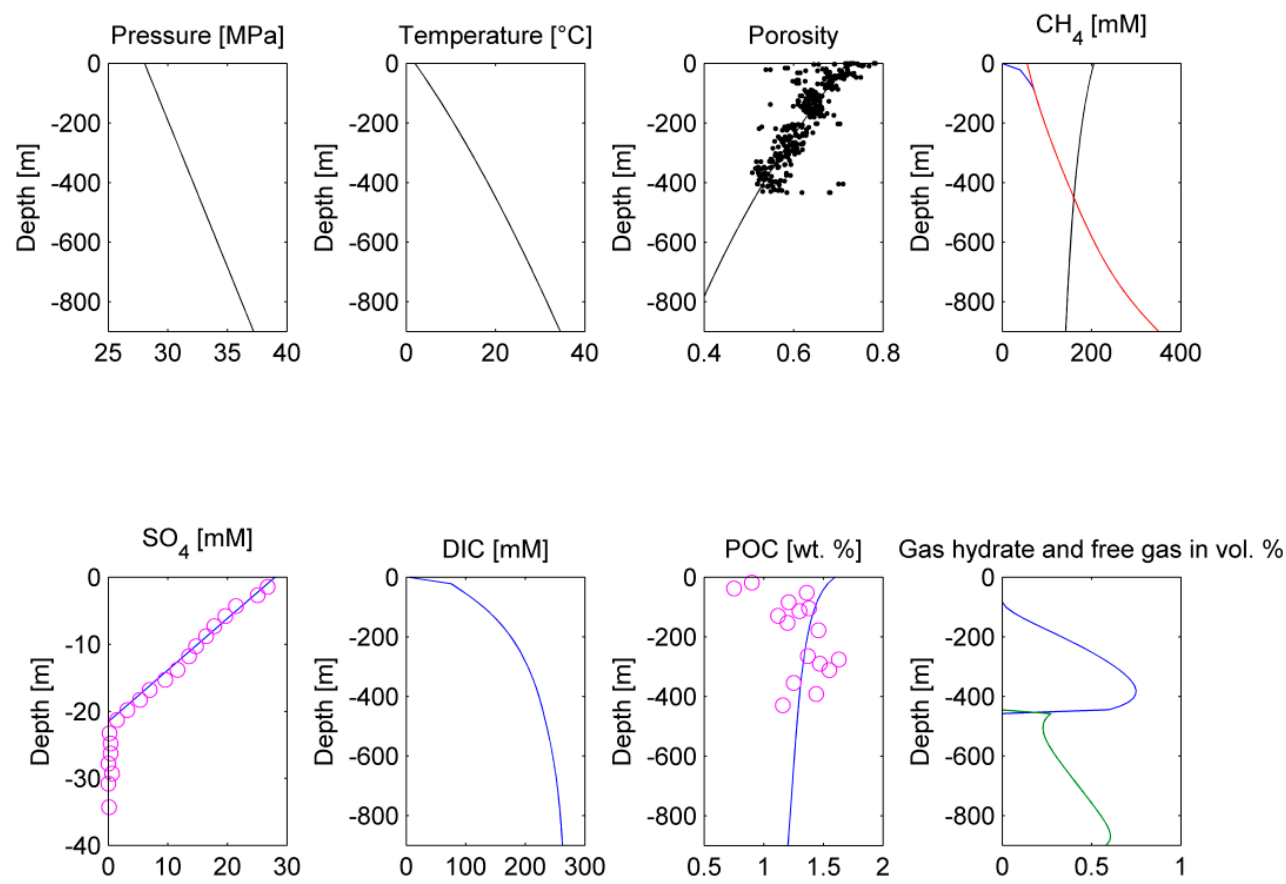

Figure 3. Modeling results for the Scenario 1. Upper panel, from the left: Pressure, temperature, porosity, and dissolved $\mathrm{CH}_{4}$ concentration plots. Porosity measurements [20] are depicted as black dots, the modeling solution is represented by the black line. On the $\mathrm{CH}_{4}$ concentration plot, red line depicts the phase boundary between gas hydrate and dissolved methane, black line represents the phase boundary between free gas and dissolved methane, and blue line states dissolved methane concentration. Gas hydrate and/or free gas formation occurs wherever dissolved methane concentration exceeds one of the solubility curves. Lower panel, from the left: $\mathrm{SO}_{4}$, dissolved inorganic carbon (DIC), POC, and gas hydrate/free gas concentration plots (in blue and green, respectively). On the $\mathrm{SO}_{4}$ and POC concentration plot, measured values are presented as pink circles [20], whereas model predictions are shown as the blue lines.
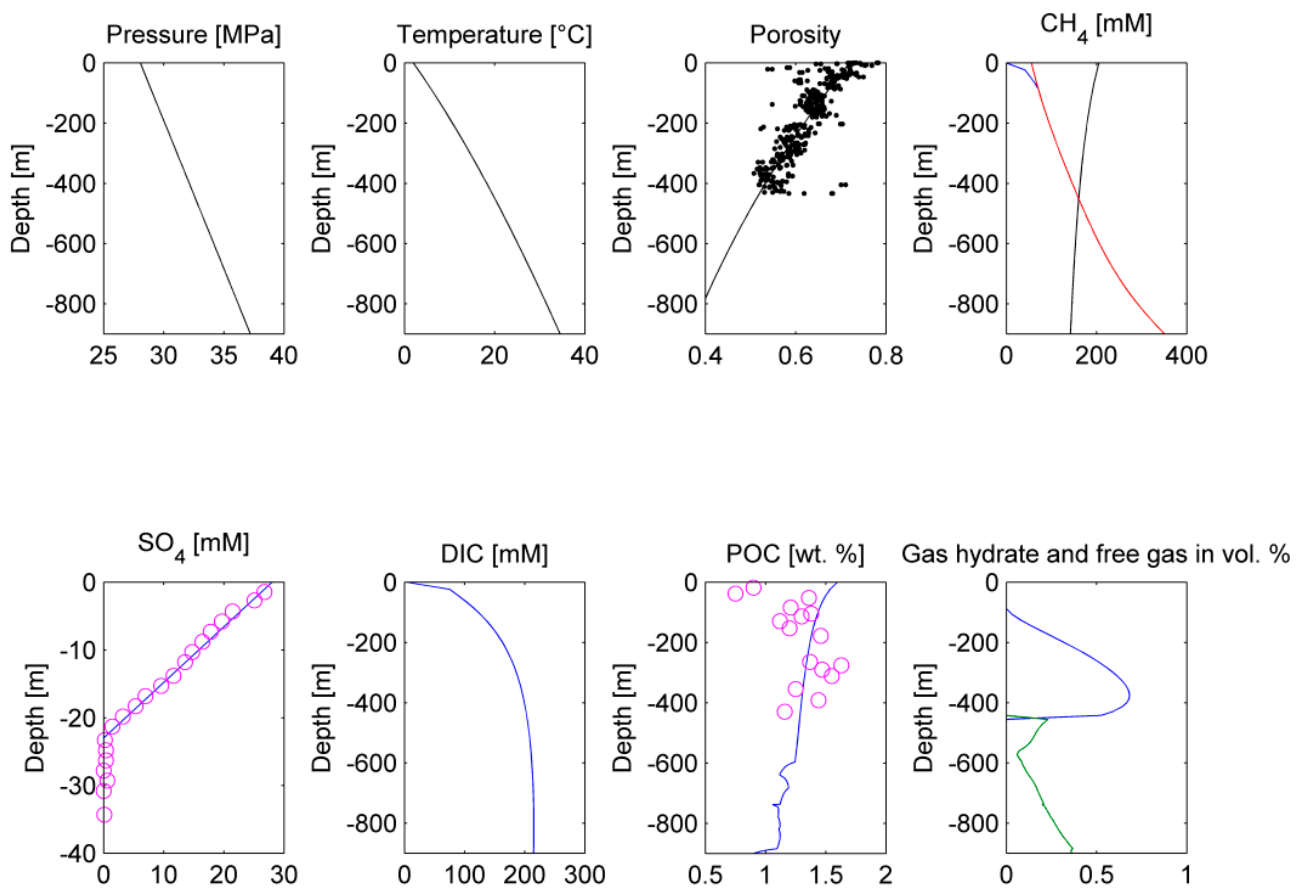

Figure 4. Modeling results of the Scenario 2a. Upper panel, from the left: Pressure, temperature, porosity, and dissolved $\mathrm{CH}_{4}$ concentration plots. Porosity measurements [20] are depicted as dots, black the 
modeling solution is represented by the black line. On the $\mathrm{CH}_{4}$ concentration plot, red line depicts the phase boundary between gas hydrate and dissolved methane, black line represents the phase boundary between free gas and dissolved methane, blue line states dissolved methane concentration. Gas hydrate and/or free gas formation occurs wherever dissolved methane concentration exceeds one of the solubility curves. Lower panel, from the left: $\mathrm{SO}_{4}$, DIC, POC, and gas hydrate/free gas concentration plots (in blue and green, respectively). On the $\mathrm{SO}_{4}$ and $\mathrm{POC}$ concentration plot, measured values are presented as pink circles [20], whereas model predictions are shown as the blue lines.
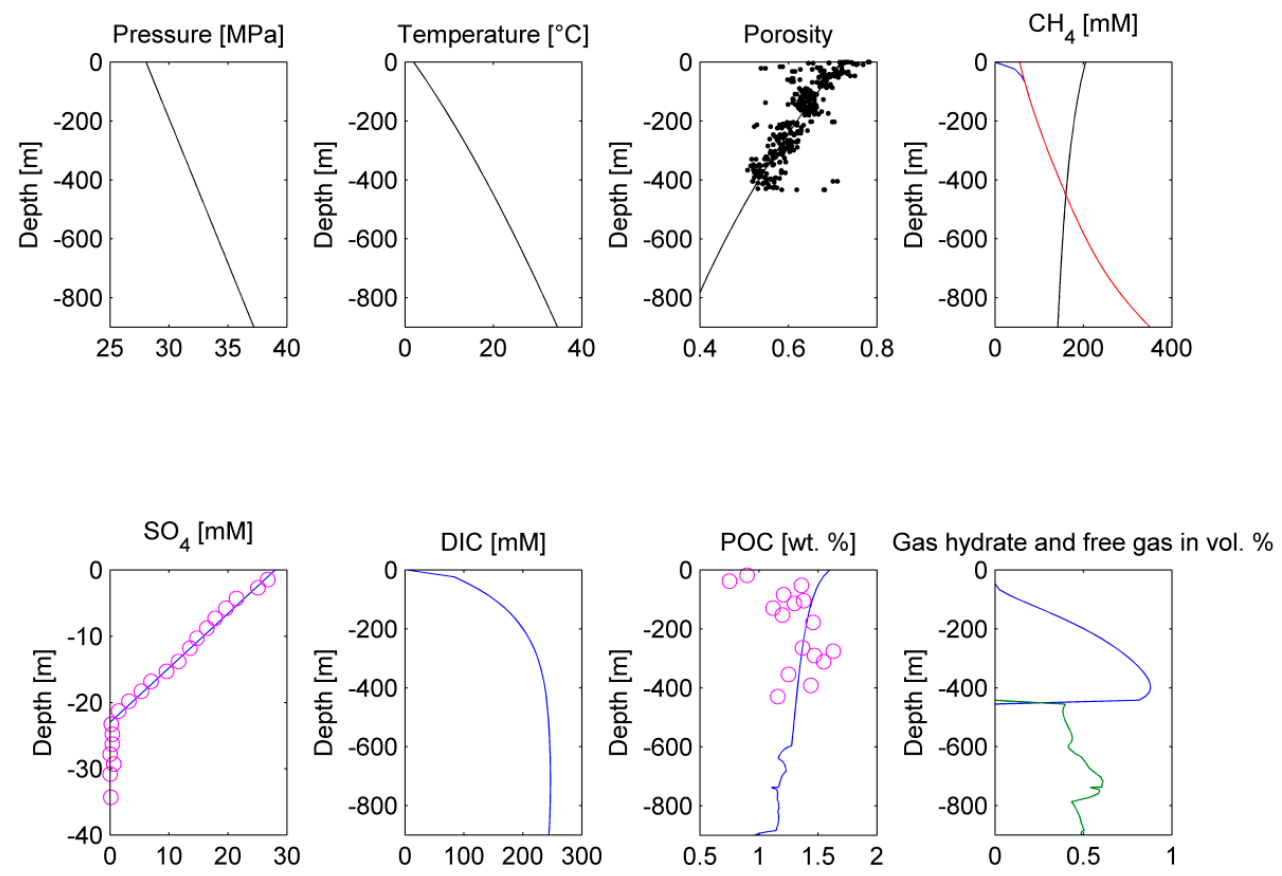

Figure 5. Modeling results of the Scenario 2b. Upper panel, from the left: Pressure, temperature, porosity, and dissolved $\mathrm{CH}_{4}$ concentration plots. Porosity measurements [20] are depicted as black dots, the modeling solution is represented by the black line. On the $\mathrm{CH}_{4}$ concentration plot, red line depicts the phase boundary between gas hydrate and dissolved methane, black line represents the phase boundary between free gas and dissolved methane, blue line states dissolved methane concentration. Gas hydrate and/or free gas formation occurs wherever dissolved methane concentration exceeds one of the solubility curves. Lower panel, from the left: $\mathrm{SO}_{4}$, DIC, POC, and gas hydrate/free gas concentration plots (in blue and green, respectively). On the $\mathrm{SO}_{4}$ and POC concentration plot, measured values are presented as pink circles [20], whereas model predictions are shown as the blue lines. 

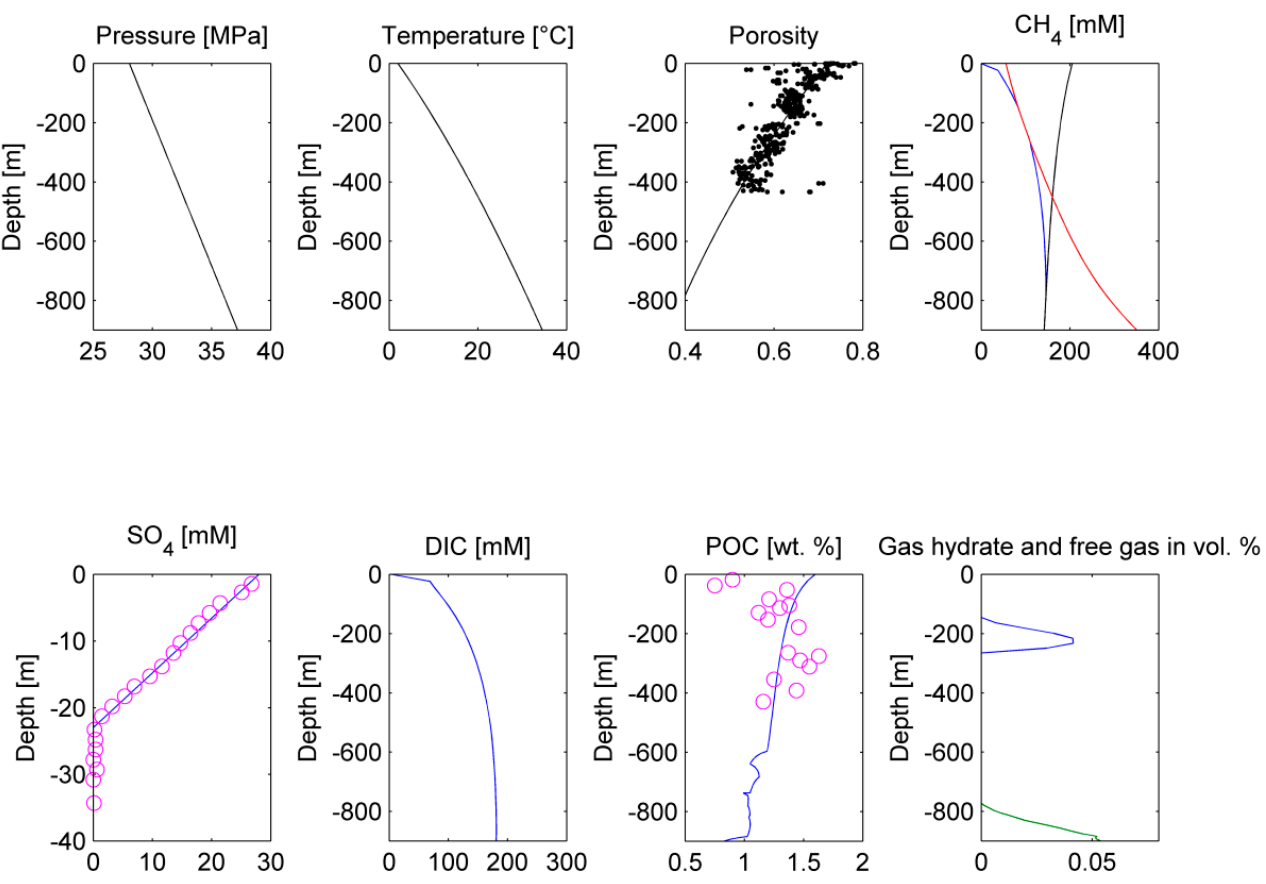

Figure 6. Modeling results of the Scenario 2c. Upper panel, from the left: Pressure, temperature, porosity, and dissolved $\mathrm{CH}_{4}$ concentration plots. Porosity measurements [20] are depicted as black dots, the modeling solution is represented by the black line. On the $\mathrm{CH}_{4}$ concentration plot, red line depicts the phase boundary between gas hydrate and dissolved methane, black line represents the phase boundary between free gas and dissolved methane, blue line states dissolved methane concentration. Gas hydrate and/or free gas formation occurs wherever dissolved methane concentration exceeds one of the solubility curves. Lower panel, from the left: $\mathrm{SO}_{4}$, DIC, POC, and gas hydrate/free gas concentration plots (in blue and green, respectively). On the $\mathrm{SO}_{4}$ and POC concentration plot, measured values are presented as pink circles [20], whereas model predictions are shown as the blue lines.
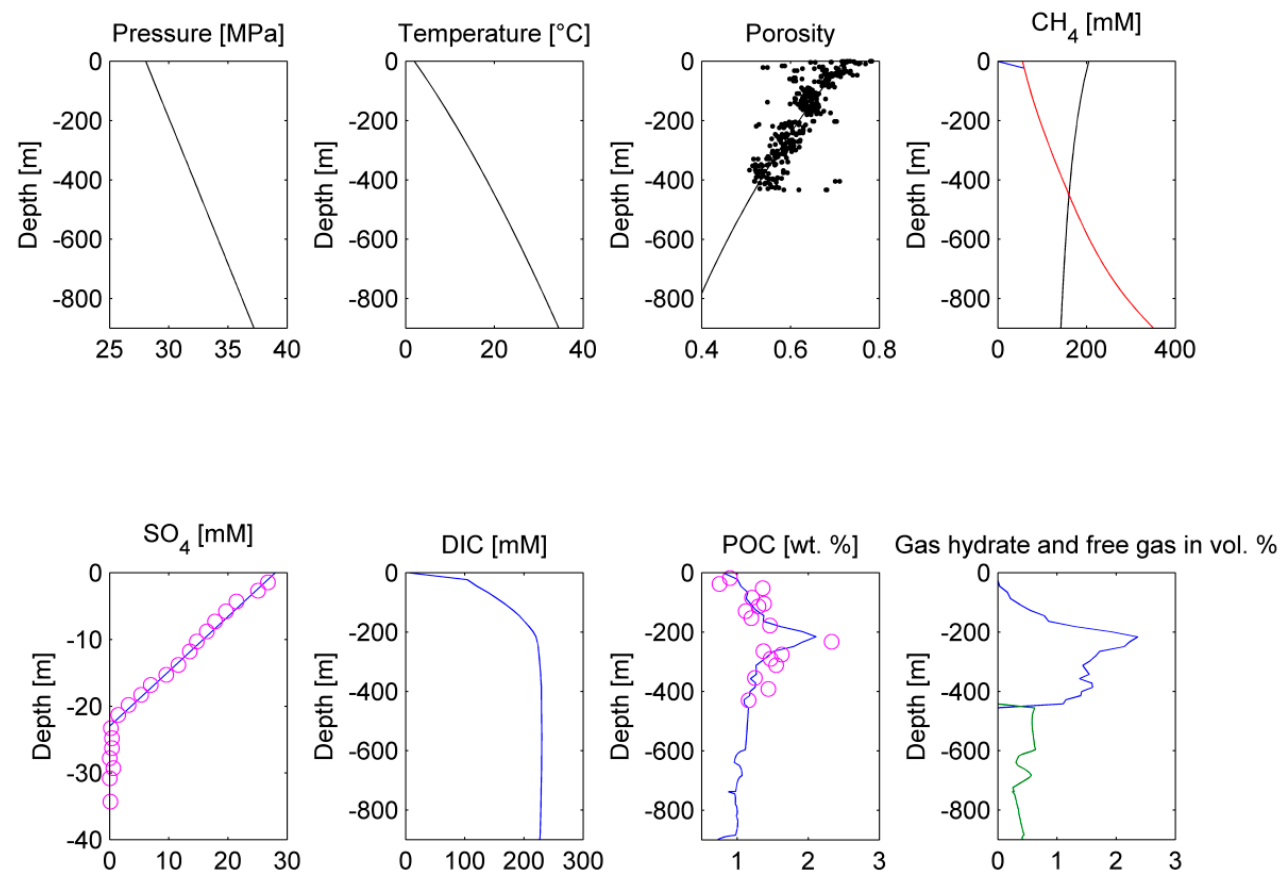

Figure 7. Modeling results of the Scenario 3. Upper panel, from the left: Pressure, temperature, porosity, and dissolved $\mathrm{CH}_{4}$ concentration plots. Porosity measurements [20] are depicted as black dots, the modeling solution is represented by the black line. On the $\mathrm{CH}_{4}$ concentration plot, red line depicts the 
phase boundary between gas hydrate and dissolved methane, black line represents the phase boundary between free gas and dissolved methane, blue line states dissolved methane concentration. Gas hydrate and/or free gas formation occurs wherever dissolved methane concentration exceeds one of the solubility curves. Lower panel, from the left: $\mathrm{SO}_{4}, \mathrm{DIC}, \mathrm{POC}$, and gas hydrate/free gas concentration plots (in blue and green, respectively). On the $\mathrm{SO}_{4}$ and POC concentration plot, measured values are presented as pink circles [20], whereas model predictions are shown as the blue lines.
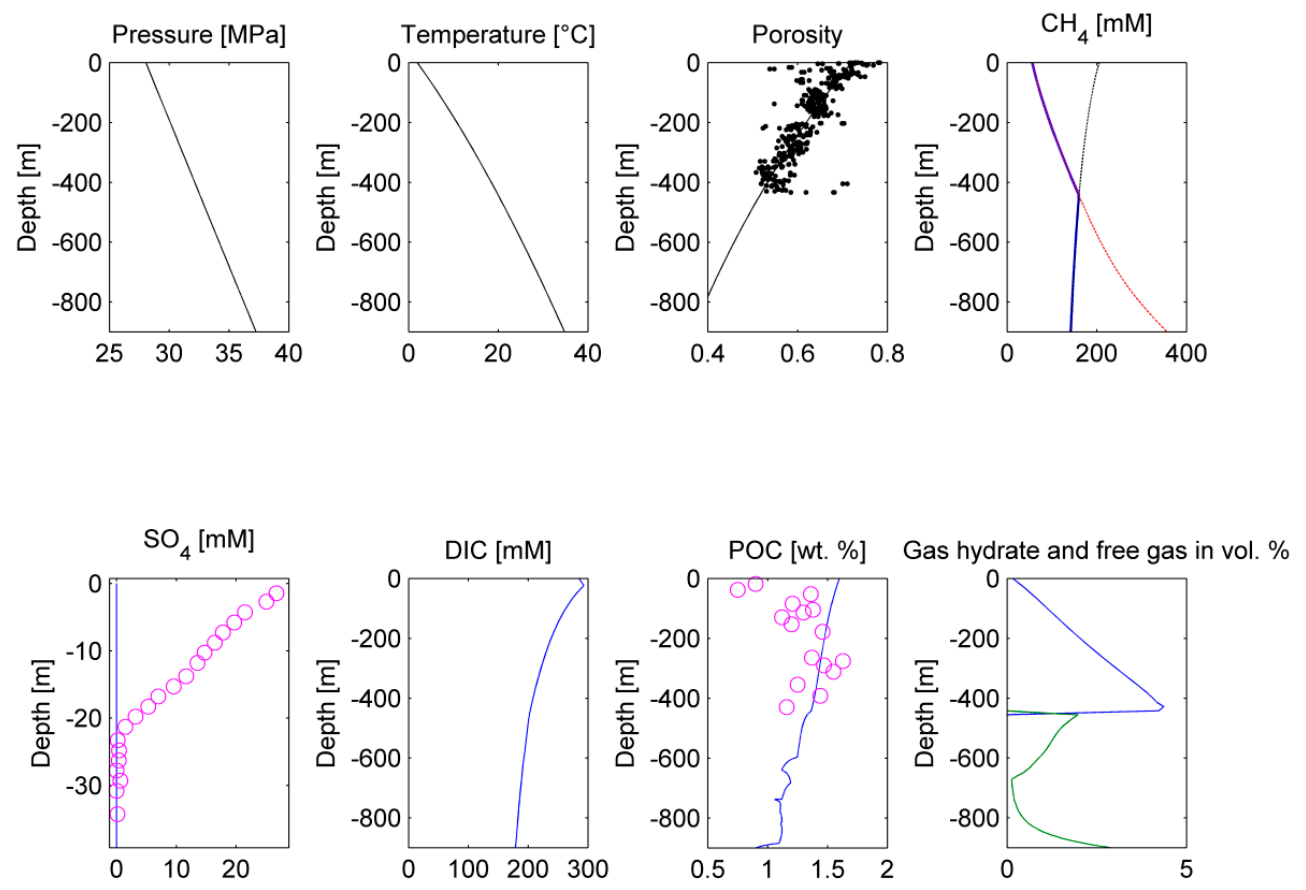

Figure 8. Modeling results of the Scenario 4. Upper panel, from the left: Pressure, temperature, porosity, and dissolved $\mathrm{CH}_{4}$ concentration plots. Porosity measurements [20] are depicted as black dots, the modeling solution is represented by the black line. On the $\mathrm{CH}_{4}$ concentration plot, red line depicts the phase boundary between gas hydrate and dissolved methane, black line represents the phase boundary between free gas and dissolved methane, blue line states dissolved methane concentration. Gas hydrate and/or free gas formation occurs wherever dissolved methane concentration exceeds one of the solubility curves. Lower panel, from the left: $\mathrm{SO}_{4}$, DIC, POC, and gas hydrate/free gas concentration plots (in blue and green, respectively). On the $\mathrm{SO}_{4}$ and POC concentration plot, measured values are presented as pink circles [20], whereas model predictions are shown as the blue lines. 

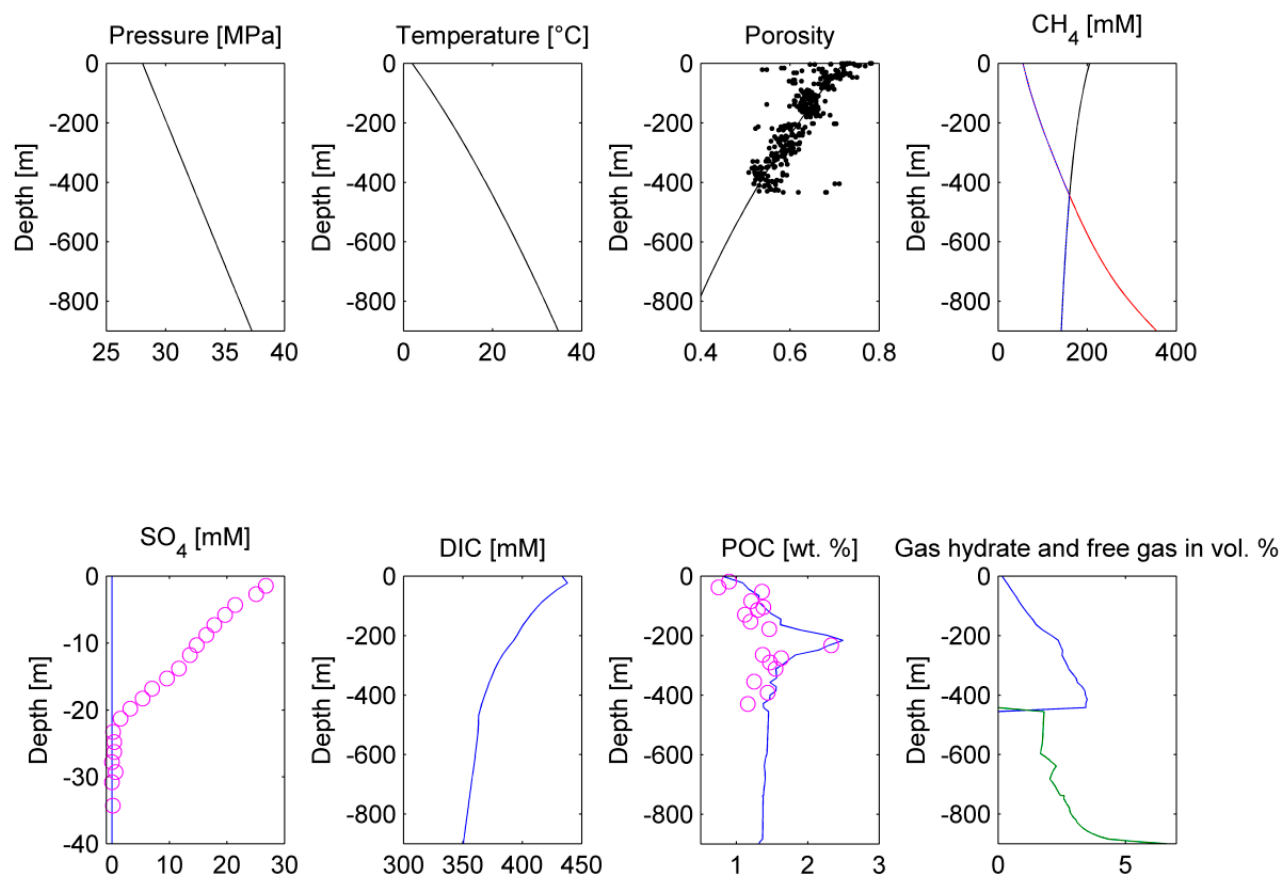

Figure 9. Modeling results of the Scenario 5. Upper panel, from the left: Pressure, temperature, porosity, and dissolved $\mathrm{CH}_{4}$ concentration plots. Porosity measurements [20] are depicted as black dots, the modeling solution is represented by the black line. On the $\mathrm{CH}_{4}$ concentration plot, red line depicts the phase boundary between gas hydrate and dissolved methane, black line represents the phase boundary between free gas and dissolved methane, blue line states dissolved methane concentration. Gas hydrate and/or free gas formation occurs wherever dissolved methane concentration exceeds one of the solubility curves. Lower panel, from the left: $\mathrm{SO}_{4}, \mathrm{DIC}, \mathrm{POC}$, and gas hydrate/free gas concentration plots (in blue and green, respectively). On the $\mathrm{SO}_{4}$ and $\mathrm{POC}$ concentration plot, measured values are presented as pink circles [20], whereas model predictions are shown as the blue lines.

\subsection{Scenario 1}

The first modeling scenario assumes that methane is only produced in-situ by organic matter degradation with a constant organic carbon concentration of $1.6 \mathrm{wt} . \%$ for the entire modeling period of $10 \mathrm{Myr}$. Sedimentation rate is constant and equals $22 \mathrm{~cm} \cdot \mathrm{kyr}^{-1}$.

This simulation run predicts maximum gas hydrate saturations of $0.75 \mathrm{vol} . \%$ at about $390 \mathrm{mbsf}$ and free gas concentrations of 0.61 vol. $\%$ (see Figure 3, Scenario 1), which poorly corresponds to the reported amounts ( 4 vol. $\%-7$ vol.\% of gas hydrates and 1 vol. $\%-2$ vol. $\%$ of gas). Net seafloor fluid velocity of about $-1.23 \times 10^{-10} \mathrm{~mm} \cdot \mathrm{s}^{-1}\left(-0.39 \mathrm{~mm} \cdot \mathrm{year}^{-1}\right)$ at the end of computational time predicts no seafloor venting. This estimate does not match the suggestions of the vent velocities estimated at $\sim 6.31 \times 10^{-12} \mathrm{~mm} \cdot \mathrm{s}^{-1}\left(0.2 \mathrm{~mm} \cdot\right.$ year $\left.^{-1}\right)$ from bromide-iodide pore water measurements [27]. However, as it was previously suggested [26], this estimate should be considered as relatively high due to pore water burial and halogens production from in-situ organic matter degradation that were not included in the study of Egeberg and Dickens [27]. Our results for Scenario 1 correlate well with the ones obtained by Wallmann et al. [26] who also used a constant rate of sedimentation throughout the modeling time frame. The predicted dissolved sulfate is, just as in Wallmann et al. [26], in good agreement with the data (see Figure 3).

\subsection{Scenario $2 a \%-c$}

In the modeling scenarios $2 \mathrm{a} \%-\mathrm{c}$, sedimentation rates vary according to the data from Ikeda et al. [37] (see Table 4). Remaining modeling parameters stay the same as in the Scenario 1. 
Additionally, two cases with diminished (by a factor of 0.5 ) and enhanced (by a factor of 2) diffusion of chemical species within pore waters were analyzed (Scenario $2 b$ and Scenario 2c, respectively).

In Scenario 2a, predicted gas hydrate saturations are highest at a depth of $390 \mathrm{mbsf}$ (see Figure 4) and are similar to the ones obtained in the Scenario 1 (0.68 vol.\%). Maximum free gas concentrations are equal to $0.4 \mathrm{vol} . \%$ and remain immobile. Thus, the influence of changing sedimentation regimes on the amount of gas hydrate formed throughout the basin history seems to be minor.

Keeping all modeling parameters constant, additional runs were performed to evaluate the influence of diminished (see Figure 5) as well as enhanced (see Figure 6) chemical diffusion of $\mathrm{CH}_{4}$, $\mathrm{DIC}$, and $\mathrm{SO}_{4}$ species on gas hydrate formation potential (Scenario $2 \mathrm{~b}$ and Scenario $2 \mathrm{c}$, respectively). Lower rates of diffusion (Scenario $2 b$ ) result in about $30 \%$ higher gas hydrates concentrations and about $50 \%$ faster formation of free gas due to longer residence times of dissolved in pore fluids methane within the GHSZ and close to its base. On the other hand, enhanced diffusion coefficients (Scenario 2c) caused faster removal of methane from the GHSZ. In this case, both gas hydrate and free gas formation was slowed down by a factor of ten.

\subsection{Scenario 3}

A third modeling scenario assumes a single source of methane from in-situ POC degradation, and variable sedimentation rates (see Table 4). In contrast to Scenarios 1 and $2 a-c$, seafloor POC concentrations vary through time according to well data.

As a result, maximum gas hydrate concentrations were observed in two zones: At the depth of about 220 mbsf (roughly 2.4 vol.\%) and at the depth of 390 mbsf (roughly 2 vol.\%), which correspond to reported gas hydrate occurrence zones [22] (see Figure 7). Noticeable free gas concentrations were predicted, firstly, in the relatively thick but shallow sediment interval underneath the base of GHSZ ( 450-600 mbsf) with concentrations of about 0.7 vol.\% and, secondly, around $680 \mathrm{mbsf}$ with concentrations of about $0.6 \mathrm{vol} . \%$. Net pore fluid velocity at the upper boundary (seafloor) equal to $-1.72 \times 10^{-10} \mathrm{~mm} \cdot \mathrm{s}^{-1}\left(-5.5 \mathrm{~mm} \cdot \mathrm{year}^{-1}\right)$ poorly correlates with conclusions derived by Egeberg and Dickens [27] suggesting an upward direction of pore fluid transport. On the other hand, sulfate concentration profile stays in a good agreement with reported data.

\subsection{Scenario 4}

The fourth modeling scenario assumes a mixed source of methane that enters the model via biogenic $\mathrm{CH}_{4}$ production and an upward fluid mass flux that contains dissolved methane. The mass of fluid entering the system through the lower boundary is assumed to be constant over modeling period of $10 \mathrm{Myr}$ and equal to $5.9 \times 10^{-9} \mathrm{~kg} \mathrm{~s}^{-1} \mathrm{~m}^{-2}$, which corresponds to an upward fluid velocity at the seafloor equal to $6.29 \times 10^{-12} \mathrm{~mm} \mathrm{~s}^{-1}$ and stays in a good agreement with the reported data [27]. Mass of dissolved in pore fluids methane that enters the sediment column through the lower boundary is equal to $1.6 \times 10^{-11} \mathrm{~kg} \mathrm{~s}^{-1} \mathrm{~m}^{-2}$, which corresponds roughly to the concentration of $170 \mathrm{mM}$.

Maximum gas hydrate concentrations obtained within this scenario are about $4.4 \mathrm{vol} \%$ at a depth of $450 \mathrm{mbsf}$ (close to the base of GHSZ) suggesting an ongoing process of gas hydrate recycling. This process has been recognized as an important hydrate-forming mechanism (e.g., [9,61]), especially in high sedimentation regimes where previously formed gas hydrates are buried deeper and out of the GHSZ due to the sediment load. Newly formed methane gas from dissolving hydrates tends to migrate upward and re-enter the GHSZ, increasing the hydrate concentration close to the stability zone base. By reconstructing depositional history of the site and simulating a growing sediment column, we were able to simulate such process. The first peak of slightly elevated free gas concentrations of about 2 vol.\% was predicted at the GHSZ base. The second concentration peak is situated close to the lower boundary of model domain ( $~ 850 \mathrm{mbsf}$ ) with concentrations of $\sim 2.5$ vol.\% (see Figure 8 ). Observed free gas concentrations are most likely immobile and do not migrate upward towards the GHSZ. The upper free gas peak seems to be related to the gas hydrate recycling process described above. 
As a result of the imposed basal pore fluid flux, the sulfate concentration profile does not match the observations. These finding of gas hydrate and free gas formation from a mixed methane source are very similar to the findings of Davie and Buffett [30,43] and [31], which obtained gas hydrate concentrations of $5 \mathrm{vol} . \%$ to $7 \mathrm{vol} \% \%$ and free gas concentrations of $3 \mathrm{vol} . \%$ to $5 \mathrm{vol} . \%$ close to bottom of modeling domain (about $850 \mathrm{mbsf}$ ). However, seafloor velocity of pore fluids equal to $0.08 \mathrm{~mm} \cdot \mathrm{year}^{-1}$ derived in cited studies does not match with a value presented here of $0.2 \mathrm{~mm} \cdot$ year $^{-1}$ [27]. Further investigation presented in the later publications (e.g., [31]), which incorporated a methane-sulfate reaction zone into modeling approach, found it rather difficult to match observed $\mathrm{SO}_{4}$ concentrations due to the presence of relatively high upward flux of pore fluids (similar effect has been also noticed in this study). Likewise, another modeling scenario presented by the same authors assuming a single methane source (upward flux of pore fluids and dissolved methane) and resulting in gas hydrate concentrations of about 3 vol. \% did not match with measured sulfate concentrations due to a rather high pore fluid flux $\left(0.26 \mathrm{~mm} \cdot \mathrm{year}^{-1}\right)$. Interestingly, maximum free gas concentrations obtained by authors ( 2 vol. $\%-3$ vol.\%) were found at the base of the GHSZ already suggesting an ongoing process of gas hydrate recycling.

\subsection{Scenario 5}

In the final, fifth modeling scenario, we have combined the approach from Scenario 3 and Scenario 4 to evaluate the influence of precisely resolved POC input rates in combination with a deep methane flux on gas hydrate and free gas formation. This scenario was expected to bring the best fit to the measured and observed gas hydrate and free gas concentrations at the investigated site.

Results from the fifth modeling scenario show maximum gas hydrate concentrations of about 4 vol.\% close to the base of GHSZ ( 450 mbsf) and about 3 vol.\% at the depth of $\sim 220 \mathrm{mbsf}$ (see Figure 9). Maximum free gas concentrations can be found at the depth of $\sim 850 \mathrm{mbsf}$ (lower boundary of modeling domain) with concentrations of around $7 \mathrm{vol} . \%$ as well as at the depth of $\sim 680 \mathrm{mbsf}$ with corresponding concentrations of around $2.5 \mathrm{vol} . \%$. It is important to notice that free gas concentrations above 5 vol. $\%-10$ vol.\% are above the residual gas fraction, so that free gas is likely to rise buoyantly through the sediment column. This process has a significant impact on gas hydrate formation via recycling, especially close to the base of GHSZ, which coincides with observations of Paull and Matsumoto [20,22]. According to the geochemical data, the AOM process responsible for methane depletion at the shallow depths is characterized by relatively low reaction rates (Scenarios 1, 2a-c, and 3). In comparison, Scenarios 4 and 5 assume an active influx of brine carrying dissolved methane through the lower boundary of modeling domain, which results in enhanced fluid outflow at the top of sedimentary column and more vivid transport of all dissolved in pore fluids chemical species. This additional mass of methane entering the system from underneath strongly affects the rates of AOM reactions in the upper section of sediments and, thus, should be considered as rather seasonal feature of the system.

\subsection{The Gas Hydrate Stability Zone Base-Evolution in Time}

Based on the modeling parameters of the second scenario, which assumes variable sedimentation rates, GHSZ base depth changes over simulation time (10 Ma) were calculated and presented in Figure 10 to discuss discrepancy between observed BSR levels and theoretical GHSZ base. It has been reported that the depth of BSR for the Blake Ridge Site 997 clearly indicated on the seismic profiles is situated $\sim 450$ mbsf. Above this depth, seismic blanking effect has been observed which indicates the presence of free gas phase directly underneath. On the other hand, some theoretical GHSZ calculations show that the present-day base of hydrate stability lies about $50 \mathrm{~m}$ deeper $[25,29]$. Similarly, at the Blake Ridge Site 995, BSR depth ( 440 mbsf) does not match the base of the theoretical GHSZ in an even more evident way (base of the GHSZ is $\sim 520 \mathrm{mbsf}$ ). Moreover, the transition between the BSR and GHSZ depths has strong indication for the co-existence of methane gas and partially dissolving gas hydrates [21]. 


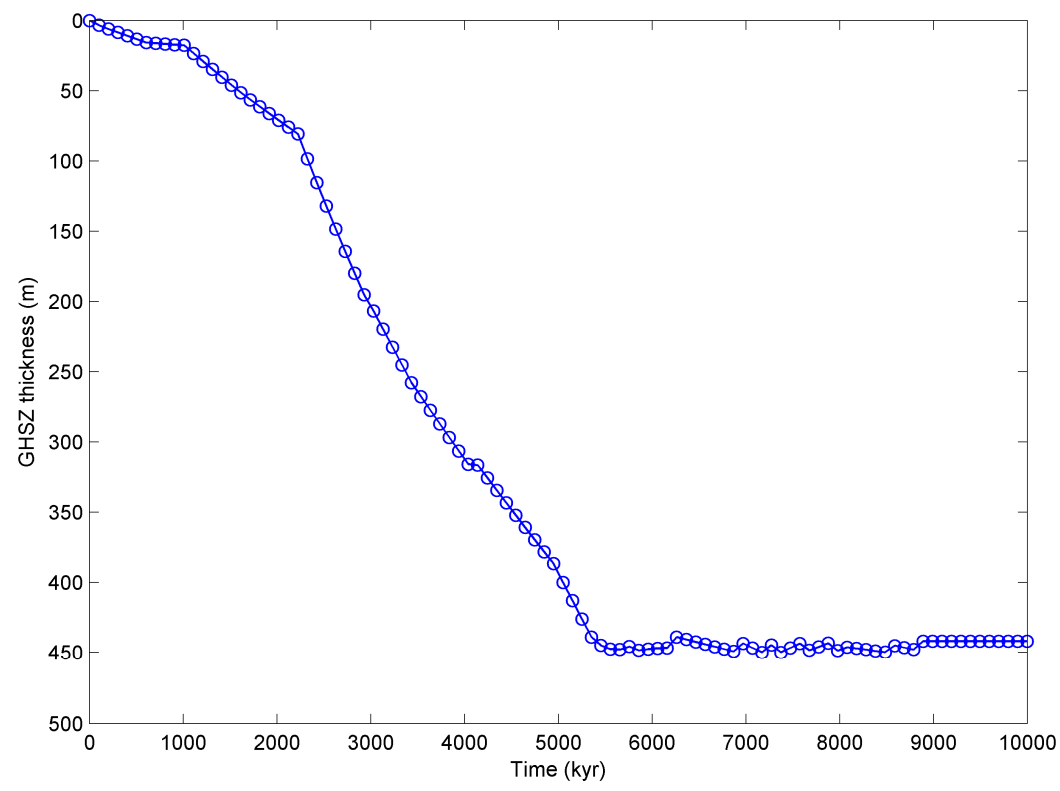

Figure 10. Gas hydrate stability zone (GHSZ) evolution in time for the Scenario 2a (no flux boundary conditions, variable sedimentation rate over time).

According to our simulations resolving for the thermal boundary conditions and full energy conservation equations, the present-day depth of the GHSZ base corresponds well with the observed BSR depth. Our predictions on the present-day sediment temperature at the BSR depth $\left(20.24{ }^{\circ} \mathrm{C}\right)$ stay in good agreement with measurements $\left(20.0^{\circ} \mathrm{C}\right)$ [20]. The evolution of the GHSZ base over the modeling period of $10 \mathrm{Myr}$ is presented in Figure 10. The present-day depth of the thermodynamic gas hydrate stability field oscillates around $450 \mathrm{mbsf}(5.4 \mathrm{Ma}-6.3 \mathrm{Ma}$ ) or $440 \mathrm{mbsf}$ (8.9 Ma-10 Ma), which makes a good fit to the reported BSR data. Periods between $6.3 \mathrm{Ma}-8.9 \mathrm{Ma}$ are characterized by slight fluctuations of the GHSZ base which, however, do not exceed $10 \mathrm{~m}$ at most.

\subsection{Model Sensitivity to the Initial Age of Organic Matter Decomposition}

We have investigated the impact of a period of low-productivity, i.e., decreased organic matter formation, that was reported [37] for the last stage of the Blake Ridge basin evolution (from $800 \mathrm{ka}$ on) in modeling Scenario 3 (see Figure 7) and Scenario 5 (see Figure 9). Scenario 3 assumed only in-situ POC decomposition as the main source of methane supply, whereas Scenario 5 simulated a mixed methane source. However, to realistically simulate methane formation dynamics, it is required to correctly evaluate the age of organic matter that could be decomposed. Figure 11 presents sensitivity analysis of the modeling Scenario 2a (variable sedimentation rates and single in-situ methane source) with respect to the initial age of organic matter decomposition entering the methanogenic zone $\left(a_{0}\right.$, see Equation (14) and Table 4). The best fit to the observed sulfate concentrations was achieved with the $a_{0}$ parameter value of $5 \times 10^{5}$ years, which stays in good agreement with previous modeling attempts [26]. Therefore, this value has been used as a constant in all other scenarios. The kinetic control on the methane oxidation process is applied as the $k_{A O M}$ parameter (see Equation (14) and Table 4) with a constant value of $1 \mathrm{~cm}^{3} \cdot$ year $^{-1} \cdot \mathrm{mmol}^{-1}$ [26] (see Figure 11). 


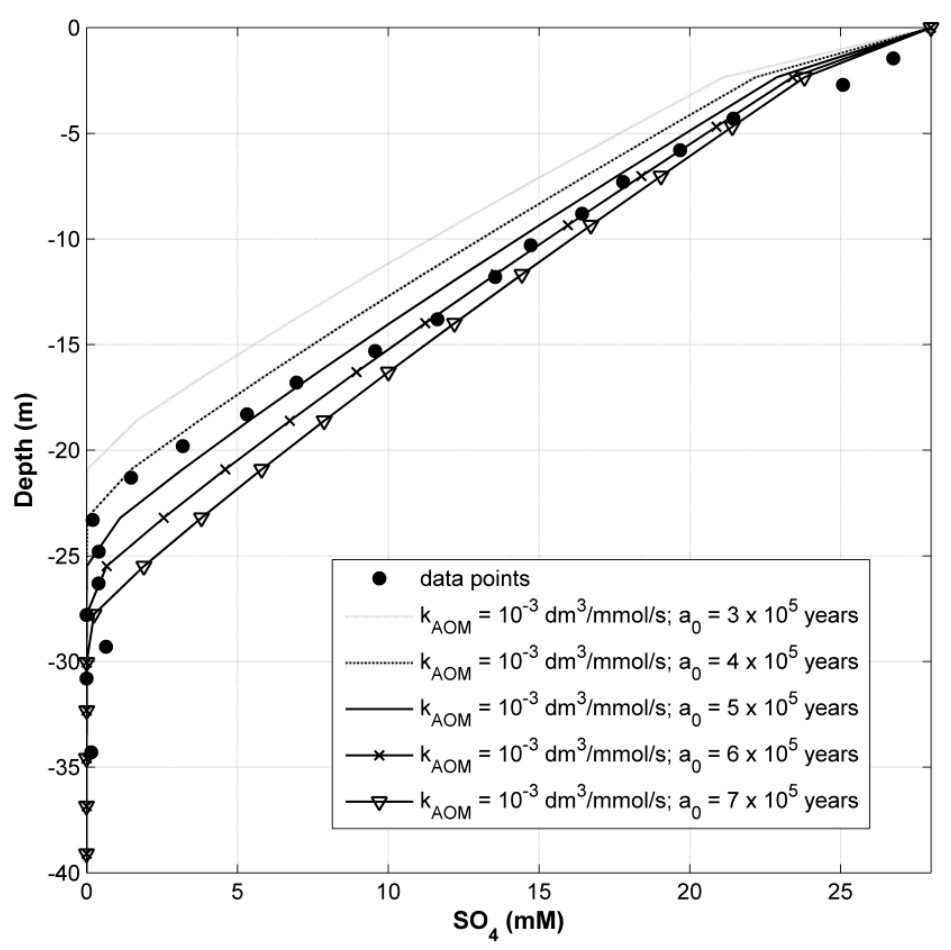

Figure 11. Sensitivity tests on the modeling results of Scenario 2a shown for the upper $40 \mathrm{~m}$ of sediments. Model sensitivity to the initial age of organic matter decomposition was explored. The best fit was obtained with a value of $5 \times 10^{5}$ years.

\section{Conclusions}

We have investigated the key processes associated with gas hydrate and free gas formation in the Blake Ridge region. Our results show that the suggested hydrate saturation of $4 \%-7 \%$ at Site 997 would require a combined source of methane from both in-situ POC degradation and a deeply sourced fluid flux. This flux was found to supply methane at a rate of $1.6 \times 10^{-11} \mathrm{~kg} \mathrm{~s}^{-1} \mathrm{~m}^{-2}$. Only slightly lower gas hydrate concentrations (up to 3.8 vol.\%) along with free gas concentrations of up to $7.25 \mathrm{vol} . \%$ are predicted for a scenario including deep methane flux and assuming time-dependent POC supply. This scenario seems to fit best some of the characteristic features of the investigated site like e.g. a second gas hydrate maximum at the depth of about $220 \mathrm{mbsf}$, which matches the observations. Moreover, the occurrence of lower than $4 \%-7 \%$ gas hydrate saturations is plausible and cannot be excluded given the uncertainty associated with chlorinity and salinity-based gas hydrate indications. The alternative scenarios, in which methane is exclusively sourced from in-situ POC degradation, results in a better fit to measured geochemical profiles including the AOM zone and, consequently, supports the theory of slightly lower than previously suggested hydrate saturations. Finally, by carefully reviewing the thermal boundary conditions and by resolving the full energy conservation equations, we were able to correctly predict the base of the GHSZ at 450 mbsf, thereby resolving a previously reported inconsistency between the location of the BSR at ODP Site 997 and the theoretical base of the GHSZ in the Blake Ridge region.

Author Contributions: Conceptualization, E.B. and L.R.; methodology, E.B. and L.R.; writing-original draft preparation, E.B.; writing-review and editing, E.B and L.R.

Funding: This research received no external funding.

Acknowledgments: We would like to thank the Managing Editor Terry Zhang and two anonymous reviewers for their help to improve the manuscript.

Conflicts of Interest: The authors declare no conflict of interest. 


\section{References}

1. Kretschmer, K.; Biastoch, A.; Ruepke, L.; Burwicz, E. Modeling the fate of methane hydrates under global warming. Glob. Biogeochem. Cycles 2015, 29, 610-625. [CrossRef]

2. Biastoch, A.; Treude, T.; Rüpke, L.H.; Riebesell, U.; Roth, C.; Burwicz, E.B.; Park, W.; Latif, M.; Böning, C.W.; Madec, G.; et al. Rising Arctic Ocean temperatures cause gas hydrate destabilization and ocean acidification. Geophys. Res. Lett. 2011, 38, 5. [CrossRef]

3. Phrampus, B.J.; Hornbach, M.J. Recent changes to the Gulf Stream causing widespread gas hydrate destabilization. Nature 2012, 490, 527-530. [CrossRef] [PubMed]

4. Skarke, A.; Ruppel, C.; Kodis, M.; Brothers, D.; Lobecker, E. Widespread methane leakage from the sea floor on the northern US Atlantic margin. Nat. Geosci. 2014, 7, 657-661. [CrossRef]

5. Berndt, C.; Feseker, T.; Treude, T.; Krastel, S.; Liebetrau, V.; Niemann, H.; Bertics, V.J.; Dumke, I.; Dünnbier, K.; Ferré, B.; et al. Temporal Constraints on Hydrate-Controlled Methane Seepage off Svalbard. Science 2014, 343, 284-287. [CrossRef] [PubMed]

6. Hillman, J.I.T.; Burwicz, E.; Zander, T.; Bialas, J.; Klaucke, I.; Feldman, H.; Drexler, T.; Awwiller, D. Investigating a gas hydrate system in apparent disequilibrium in the Danube Fan, Black Sea. Earth Planet. Sci. Lett. 2018, 502, 1-11. [CrossRef]

7. Minshull, T.A.; Marín-Moreno, H.; Betlem, P.; Bialas, J.; Buenz, S.; Burwicz, E.; Cameselle, A.L.; Cifci, G.; Giustiniani, M.; Hillman, J.I.T.; et al. Hydrate occurrence in Europe: A review of available evidence. Mar. Pet. Geol. 2019. [CrossRef]

8. Dumke, I.; Burwicz, E.; Berndt, C.; Klaeschen, D.; Feseker, T.; Geissler, W.H.; Sarkar, S. Gas hydrate distribution and hydrocarbon maturation north of the Knipovich Ridge, western Svalbard margin. J. Geophys. Res. Solid Earth 2016, 121, 1405-1424. [CrossRef]

9. Burwicz, E.; Reichel, T.; Wallmann, K.; Rottke, W.; Haeckel, M.; Hensen, C. 3-D basin-scale reconstruction of natural gas hydrate system of the Green Canyon, Gulf of Mexico. Geochem. Geophys. Geosyst. 2017, 18, 1959-1985. [CrossRef]

10. Milkov, A.V. Global estimates of hydrate-bound gas in marine sediments: How much is really out there? Earth Sci. Rev. 2004, 66, 183-197. [CrossRef]

11. Boswell, R.; Collett, T.S. Current perspectives on gas hydrate resources. Energy Environ. Sci. 2011, 4, 1206-1215. [CrossRef]

12. Burwicz, E.B.; Ruepke, L.H.; Wallmann, K. Estimation of the global amount of submarine gas hydrates formed via microbial methane formation based on numerical reaction-transport modeling and a novel parameterization of Holocene sedimentation. Geochim. Cosmochim. Acta 2011, 75, 4562-4576. [CrossRef]

13. Buffett, B.; Archer, D. Global inventory of methane clathrate: Sensitivity to changes in the deep ocean. Earth Planet. Sci. Lett. 2004, 227, 185-199. [CrossRef]

14. Klauda, J.B.; Sandler, S.I. Global Distribution of Methane Hydrate in Ocean Sediment. Energy Fuels 2005, 19, 459-470. [CrossRef]

15. Dickens, G.R. The potential volume of oceanic methane hydrates with variable external conditions. Org. Geochem. 2001, 32, 1179-1193. [CrossRef]

16. Wallmann, K.; Piñero, E.; Burwicz, E.; Haeckel, M.; Hensen, C.; Dale, A.W.; Rüpke, L.H. The Global Inventory of Methane Hydrate in Marine Sediments: A Theoretical Approach. Energies 2012, 5, 2449-2498. [CrossRef]

17. Archer, D.; Buffett, B.; Brovkin, V. Ocean methane hydrates as a slow tipping point in the global carbon cycle. Proc. Natl. Acad. Sci. USA 2009, 106, 20596-20601. [CrossRef] [PubMed]

18. USGS World Energy Assessment Team. US Geological Survey World Petroleum Assessment 2000-Description and Results; U.S. Geological Survey: Reston, VA, USA, 2000.

19. Shipley, T.H.; Houston, M.H.; Buffler, R.T.; Shaub, F.J.; McMillen, K.J.; Ladd, J.W.; Worzel, J.L. Seismic Evidence for Widespread Possible Gas Hydrate Horizons on Continental Slopes and Rises. Aapg Bull. Am. Assoc. Pet. Geol. 1979, 63, 2204-2213.

20. Paull, C.K.; Matsumoto, R.; Wallace, P.J. 9. Site 997, Shipboard Scientific Party. In Proceeding of the Ocean Drilling Program, Initial Reports; Texas A\&M University: College Station, TX, USA, 1996; Volume 164.

21. Guerin, G.; Goldberg, D.; Melser, A. Characterization of in situ elastic properties of gas hydrate-bearing sediments on the Blake Ridge. J. Geophys. Res. 1999, 104, 17781-17795. [CrossRef] 
22. Paull, C.K.; Matsumoto, R. 1. Leg 164 Overview. In Proceeding of the Ocean Drilling Program, Scientific Results; Texas A\&M University: College Station, TX, USA, 2000; Volume 164.

23. Bunz, S.; Polyanov, S.; Vadakkepuliyambatta, S.; Consolaro, C.; Mienert, J. Active gas venting through hydrate-bearing sediments on the Vestnesa Ridge, offshore W-Svalbard. Mar. Geol. 2012, 332, 189-197. [CrossRef]

24. Rajan, A.; Mienert, J.; Bunz, S. Acoustic evidence for a gas migration and release system in Arctic glaciated continental margins offshore NW-Svalbard. Mar. Pet. Geol. 2012, 32, 36-49. [CrossRef]

25. Garg, S.K.; Pritchett, J.W.; Katoh, A.; Baba, K.; Fujii, T. A mathematical model for the formation and dissociation of methane hydrates in the marine environment. J. Geophys. Res. 2008, 113. [CrossRef]

26. Wallmann, K.; Aloisi, G.; Haeckel, M.; Obzhirov, A.; Pavlova, G.; Tishchenko, P. Kinetics of organic matter degradation, microbial methane generation, and gas hydrate formation in anoxic marine sediments. Geochim. Cosmochim. Acta 2006, 70, 3905-3927. [CrossRef]

27. Egeberg, P.K.; Dickens, G.R. Thermodynamic and pore water halogen constraints on gas hydrate distribution at ODP Site 997 (Blake Ridge). Chem. Geol. 1999, 153, 53-79. [CrossRef]

28. Davie, M.K.; Buffett, B.A. A numerical model for the formation of gas hydrate below the seafloor. In Proceedings of the Rock the Foundation Convention, Canadian Society of Petroleum Geologists, Calgary, AB, Canada, 18-22 June 2001.

29. $\mathrm{Xu}, \mathrm{W}$.; Ruppel, C. Predicting the occurence, distribution, and evolution of methane gas hydrate in porous marine sediments. J. Geophys. Res. 1999, 104, 5081-5095. [CrossRef]

30. Davie, M.K.; Buffett, B.A. Sources of methane for marine gas hydrate: Inferences from a comparison of observations and numerical models. Earth Planet. Sci. Lett. 2003, 206, 51-63. [CrossRef]

31. Davie, M.K.; Buffett, B.A. A steady-state model for marine hydrate formation: Constraints on methane supply from pore water sulfate profiles. J. Geophys. Res. 2003, 108. [CrossRef]

32. Claypool, G.E.; Kaplan, I.R. Natural Gases in Marine Sediments; Kaplan, I.R., Ed.; Plenum Press: New York, NY, USA, 1974; Volume 3, pp. 99-139.

33. Borowski, W.S.; Paull Ch, K.; Ussler, I.I.I.W. Carbon cycling within the upper methanogenic zone of continental rise sediments: An example from the methane-rich sediments overlying the Blake Ridge gas hydrate deposits. Mar. Chem. 1997, 57, 299-311. [CrossRef]

34. Bryan, G.M. Hydrodynamic model of blake outer ridge. J. Geophys. Res. 1970, 75, 4530-4537. [CrossRef]

35. Hornbach, M.J.; Saffer, D.M.; Holbrook, W.S. Critically pressured free-gas reservoirs below gas-hydrate provinces. Nature 2004, 427, 142-144. [CrossRef]

36. Flemings, P.B.; Liu, X.L.; Winters, W.J. Critical pressure and multiphase flow in Blake Ridge gas hydrates. Geology 2003, 31, 1057-1060. [CrossRef]

37. Ikeda, A.; Okada, H.; Koizumi, I. 35. Data Report: Late Miocene to Pleistocene Diatoms from the Blake Ridge, Site 997. In Proceeding of the Ocean Drilling Program, Scientific Results; Texas A\&M University: College Station, TX, USA, 2000; Volume 164.

38. Paull, C.K.; Lorenson, T.D.; Borowski, W.S.; Ussler, W., III; Olsen, K.; Rodriguez, N.M. 7. Isotopic Composition of $\mathrm{CH}_{4}, \mathrm{CO}_{2}$ species, and sedimentary organic matter within samples from the Blake Ridge: Gas source implications. In Proceeding of the Ocean Drilling Program, Scientific Results; Texas A\&M University: College Station, TX, USA, 2000; Volume 164.

39. Dillon, W.P.; Paull, C.K. Natural Gas Hydrates: Properties, Occurrences, and Recovery; Cox, J.L., Ed.; Butterworth: Oxford, UK, 1983; pp. 73-90.

40. Dickens, G.R.; Paull, C.K.; Wallace, P. Direct measurement of in situ methane quantities in a large gas-hydrate reservoir. Nature 1997, 385, 426-428. [CrossRef]

41. Hovland, M.; Gallagher, J.W.; Clennell, M.B.; Lekvam, K. Gas hydrate and free gas volumes in marine sediments: Example from the Niger Delta front. Mar. Pet. Geol. 1997, 14, 245-255. [CrossRef]

42. Ruppel, C. Anomalously cold temperatures observed at the base of the gas hydrate stability zone on the US Atlantic passive margin. Geology 1997, 25, 699-702. [CrossRef]

43. Davie, M.K.; Buffett, B.A. A numerical model for the formation of gas hydrate below the seafloor. J. Geophys. Res. Solid Earth 2001, 106, 497-514. [CrossRef]

44. Tishchenko, P.; Hensen Ch Wallmann, K.; Wong, C.S. Calculation of the stability and solubility of methane hydrate in seawater. Chem. Geol. 2005, 219, 37-52. [CrossRef] 
45. Hantschel, T.; Kauerauf, A. Fundamentals of Basin and Petroleum Systems Modeling; Springer: Berlin/Heidelberg, Germany, 2009.

46. Parker, J.C.; Lenhard, R.J.; Kuppusamy, T. A parametric model for constitutive properties governing multiphase flow in porous media. Water Resour. Res. 1987, 23, 618-624. [CrossRef]

47. $\mathrm{Xu}, \mathrm{W}$; Germanovich, L.N. Excess pore pressure resulting from methane hydrate dissociation in marine sediments: A theoretical approach. J. Geophys. Res. 2006, 111. [CrossRef]

48. Friend, D.G.; Ely, J.F.; Ingham, H. Thermophysical properties of methane. J. Phys. Chem. Ref. Data 1989, 18, 583-638. [CrossRef]

49. Doughty, C. Modeling geologic storage of carbon dioxide: Comparison of non-hysteretic and hysteretic characteristic curves. Energy Convers. Manag. 2007, 48, 1768-1781. [CrossRef]

50. Manakov, A.Y.; Likhacheva, A.Y.; Potemkin, V.A.; Ogienko, A.G.; Kurnosov, A.V.; Ancharov, A.I. Compressibility of Gas Hydrates. ChemPhysChem 2011, 12, 2475-2483. [CrossRef] [PubMed]

51. Gabitto, J.F.; Tsouris, C. Physical Properties of Gas Hydrates: A Review. J. Thermodyn. 2010, 2010. [CrossRef]

52. Rueff, R.M.; Sloan, E.D.; Yesavage, V.F. Heat-capacity and heat of dissociation of methane hydrates. AIChE J. 1988, 34, 1468-1476. [CrossRef]

53. Boudreau, B.P. Diagenetic Models and Their Implementation: Modelling Transport and Reactions in Aquatic Sediments; Springer: Berlin/Heidelberg, Germany, 1997.

54. Flogel, S.; Wallmann, K.; Poulsen, C.J.; Zhou, J.; Oschlies, A.; Voigt, S.; Kuhnt, W. Simulating the biogeochemical effects of volcanic $\mathrm{CO} 2$ degassing on the oxygen-state of the deep ocean during the Cenomanian/Turonian Anoxic Event (OAE2). Earth Planet. Sci. Lett. 2011, 305, 371-384. [CrossRef]

55. Middelburg, J.J. A simple rate model for organic matter decomposition in marine sediments. Geochim. Cosmochim. Acta 1989, 53, 1577-1581. [CrossRef]

56. McDougall, T.J.; Jackett, D.R.; Millero, F.J.; Pawlowicz, R.; Barker, P.M. A global algorithm for estimating Absolute Salinity. Ocean Sci. 2012, 8, 1117-1128. [CrossRef]

57. Duan, Z.; Moller, N.; Weare, J.H. An equation of state for the $\mathrm{CH}_{4}-\mathrm{CO}_{2}-\mathrm{H}_{2} \mathrm{O}$ system: I. Pure systems from 0 to $1000{ }^{\circ} \mathrm{C}$ and 0 to 8000 bar. Geochim. Cosmochim. Acta 1992, 56, 2605-2617. [CrossRef]

58. Deming, D.; Chapman, D.S. Thermal Histories and Hydrocarbon Generation-Example from Utah-Wyoming Thrust Belt. Aapg Bull. Am. Assoc. Pet. Geol. 1989, 73, 1455-1471.

59. Waite, W.F.; Stern, L.A.; Kirby, S.H.; Winters, W.J.; Mason, D.H. Simultaneous determination of thermal conductivity, thermal diffusivity and specific heat in Si methane hydrate. Geophys. J. Int. 2007, 169, 767-774. [CrossRef]

60. Schmidt, C.; Burwicz, E.; Hensen, C.; Wallmann, K.; Martinez-Loriente, S.; Gracia, E. Genesis of mud volcano fluids in the Gulf of Cadiz using a novel basin-scale model approach. Geochim. Cosmochim. Acta 2018, 243, 186-204. [CrossRef]

61. Karstens, J.; Haflidason, H.; Becker, L.W.M.; Berndt, C.; Rüpke, L.; Planke, S.; Liebetrau, V.; Schmidt, M.; Mienert, J. Glacigenic sedimentation pulses triggered post-glacial gas hydrate dissociation. Nat. Commun. 2018, 9, 11. [CrossRef] [PubMed]

(C) 2019 by the authors. Licensee MDPI, Basel, Switzerland. This article is an open access article distributed under the terms and conditions of the Creative Commons Attribution (CC BY) license (http://creativecommons.org/licenses/by/4.0/). 